\title{
Influence of cross-shelf water transport on nutrients and phytoplankton in the East China Sea: a model study
}

\author{
L. Zhao ${ }^{1}$ and X. Guo ${ }^{1,2}$ \\ ${ }^{1}$ Physical Oceanography Laboratory, Ocean University of China, 238 Songling Road, Qingdao 266100, China \\ ${ }^{2}$ Center for Marine Environmental Studies, Ehime University, 2-5 Bunkyo-Cho, Matsuyama 790-8577, Japan \\ Received: 12 June 2010 - Published in Ocean Sci. Discuss.: 26 July 2010 \\ Revised: 31 December 2010 - Accepted: 5 January 2011 - Published: 17 January 2011
}

\begin{abstract}
A three dimensional coupled biophysical model was used to examine the supply of oceanic nutrients to the shelf of the East China Sea (ECS) and its role in primary production over the shelf. The model consisted of two parts: the hydrodynamic module was based on a nested model with a horizontal resolution of 1/18 degree, whereas the biological module was a lower trophic level ecosystem model including two types of phytoplankton, three elements of nutrients, and biogenic organic material. The model results suggested that seasonal variations occurred in the distribution of nutrients and chlorophyll $a$ over the shelf of the ECS. After comparison with available observed nutrients and chlorophyll $a$ data, the model results were used to calculate volume and nutrients fluxes across the shelf break. The annual mean total fluxes were $1.53 \mathrm{~Sv}$ for volume, $9.4 \mathrm{kmol} \mathrm{s}^{-1}$ for DIN, $0.7 \mathrm{kmol} \mathrm{s}^{-1}$ for DIP, and $18.2 \mathrm{kmol} \mathrm{s}^{-1}$ for silicate. Two areas, northeast of Taiwan and southwest of Kyushu, were found to be major source regions of oceanic nutrients to the shelf. Although the onshore fluxes of nutrients and volume both had apparent seasonal variations, the seasonal variation of the onshore nutrient flux did not exactly follow that of the onshore volume flux. Additional calculations in which the concentration of nutrients in Kuroshio water was artificially increased suggested that the oceanic nutrients were distributed in the bottom layer from the shelf break to the region offshore of the Changjiang estuary from spring to summer and appeared in the surface layer from autumn to winter. The calculations also implied that the supply of oceanic nutrients to the shelf can change the consumption of pre-existing nutrients from rivers. The response of primary production over the shelf to the oceanic nutrients was confirmed not only in the surface
\end{abstract}

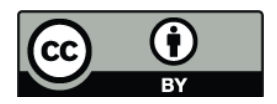

Correspondence to: X. Guo (guoxinyu@ sci.ehime-u.ac.jp) layer (mainly at the outer shelf and shelf break in winter and in the region offshore of the Changjiang estuary in summer) but also in the subsurface layer over the shelf from spring to autumn.

\section{Introduction}

In addition to receiving the terrestrial input of nutrients, marginal seas also receive nutrients from the open ocean (hereafter referred to oceanic nutrients) through cross-shelf water exchange. Over a timescale of several decades, terrestrial inputs are affected by both anthropogenic activities and climate change, while oceanic nutrients are mainly affected by climate change. Quantifying the oceanic nutrient flux and evaluating its role in driving primary production in marginal seas therefore addresses two key issues in understanding the potential influences of climate change on these economically and ecologically important ecosystems.

The East China Sea (ECS) is one of the major marginal seas of the northwestern Pacific (Fig. 1). Many rivers, including the Changjiang River (Yangtze River), provide a substantial input of freshwater and nutrients into adjacent seas (Zhang, 1996). On the other hand, the ECS also receives water and associated nutrients from the South China Sea through the Taiwan Strait, for which the volume transport is greater than river discharge into the ECS by as much as two orders of magnitude (Isobe, 2008). In addition to the Taiwan Strait, Chen (2008) suggested that the upwelling of the South China Sea water on the western side of the Kuroshio in the ECS is also a possible pathway for the nutrients transported from the South China Sea to the ECS. The Kuroshio in the ECS flows along the shelf break (see 200-m isobath in Fig. 1), and the onshore volume transport of the Kuroshio

Published by Copernicus Publications on behalf of the European Geosciences Union. 


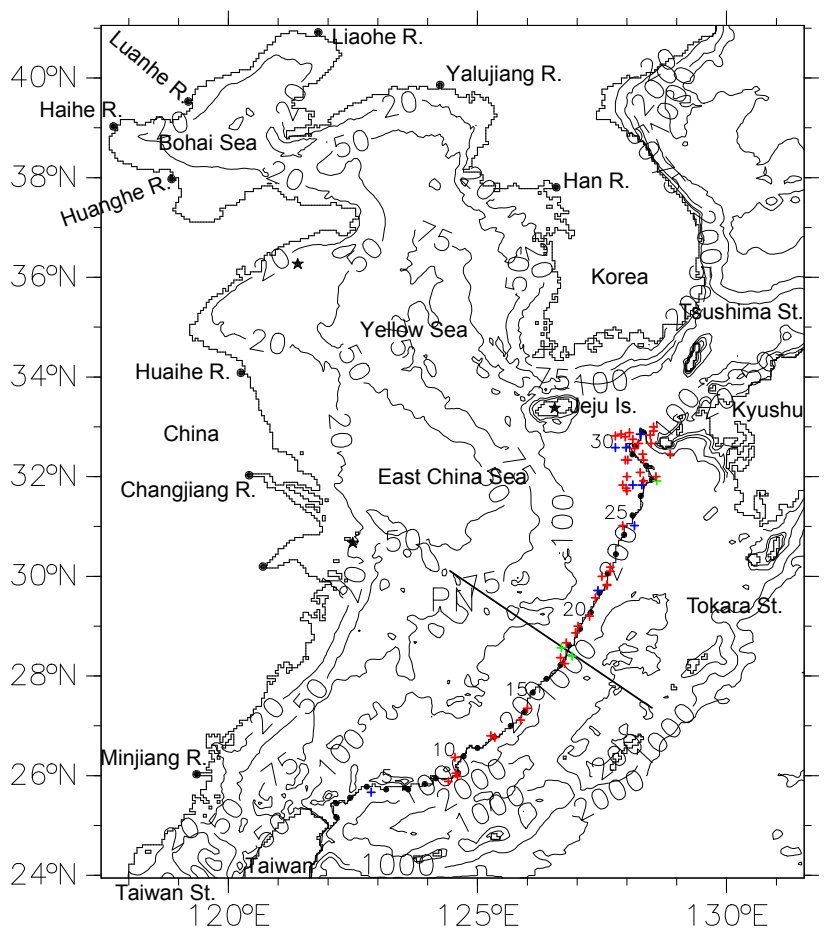

Fig. 1. Model domain and bathymetry. Rivers are denoted by dots around the coastline; three observation sites for atmospheric dry and wet deposition of nutrients are denoted by stars; and observation stations for the data used in Fig. 8 are denoted by crosses. Red means data number less than 10 , blue means data number between 10 and 40, and green means data number more than 40. Numbered contours are isobaths in meters. The 200-m isobath along the shelf break is overlapped by a line with dots and numbers, across which the fluxes of volume and nutrients are calculated and presented in Figs. 9-11.

across the break has been reported to be of the same order as the transport through the Taiwan Strait (Guo et al., 2006; Isobe, 2008).

There are strong seasonal variations in the spatial distribution of nutrients in the ECS (Chen, 2009). The concentration of surface nutrients in the ECS is high in winter, is depleted in spring and summer, and reverts smoothly in autumn to the winter concentration (Wang, et al., 2003; Chen, 2009). Such seasonal variations are tightly coupled to biological processes such as phytoplankton blooms in spring and summer and the remineralization of detritus in autumn as well as to physical processes such as summer stratification and winter mixing. In addition, seasonal changes in inputs of terrestrial nutrients from rivers and of oceanic nutrients from the Taiwan Strait and the shelf break are also important to the concentration of nutrients in the ECS.

Using a box model, Chen and Wang (1999) calculated the annual nutrient budget over the shelf of the ECS and suggested that the Kuroshio subsurface water has a more important role in supplying nutrients onto the ECS shelf than rivers do. Zhang et al. (2007b) revisited this calculation using data collected in summer and winter, and confirmed that nutrients supplied by Kuroshio subsurface water intrusion onto the shelf were important in both seasons, particularly for phosphate. These findings are supported by the distribution over the shelf of a passive tracer released only in the Kuroshio region east of Taiwan in a three dimensional numerical model (Guo et al., 2006).

Although oceanic nutrients have been shown to be important to the nutrient budget of the ECS (Chen and Wang, 1999; Zhang et al., 2007b), it is still unknown whether they are readily utilized by phytoplankton over the shelf. If oceanic nutrients significantly contribute to primary production over the shelf in the ECS, we should clarify where and when primary production supported by oceanic nutrients occurs. In this study, we applied a three dimensional numerical biophysical model to examine the onshore flux of oceanic nutrients across the shelf break, paying special attention to its spatial distribution along the shelf break, and to examine where and when the primary production over the shelf in the ECS responds to oceanic nutrients.

After configuring the model (described in Sect. 2), we compared the model results (nutrients and chlorophyll $a$ ) with observational data and examined the nutrient flux across the ECS shelf break by presenting its spatial distribution along the shelf break and its seasonal variations. This work is described in Sect. 3. We changed the concentration of nutrients in the Kuroshio water, and reran the simulations to examine changes in concentrations of nutrients and chlorophyll $a$ over the ECS shelf and in the onshore nutrient flux across the shelf break. This is described in Sect. 4. Finally, we summarize this study in Sect. 5 .

\section{Model configuration and data sources}

Our model consisted of two parts: a hydrodynamic module and a biological module. The hydrodynamic module provided physical parameters, such as water temperature, velocities and diffusivity coefficients, to the biological module. The two modules were run simultaneously in coupled runs.

The hydrodynamic module is based on the Princeton Ocean Model (Blumberg and Mellor, 1987; Mellor, 2003) and is configured with a nesting method to obtain a high horizontal resolution (1/18 degree) for the ECS, as described in detail by Guo et al. (2003). In the vertical direction, 21 sigma levels were used. Differences from the previous version were the explicit inclusion of freshwater input from the sea surface and rivers and the addition of tidal forcing $\left(\mathrm{M}_{2}, \mathrm{~S}_{2}, \mathrm{~K}_{1}\right.$ and $\mathrm{O}_{1}$ tides) along the lateral boundary (Wang et al., 2008).

The biological module (Fig. 2) is based on the biological part of NORWECOM (Aksnes et al., 1995; Skogen et al., 1995; Skogen and Søiland, 1998) and is reconstructed for the ECS. The model components include three elements of nutrients (dissolved inorganic nitrogen (DIN), dissolved 


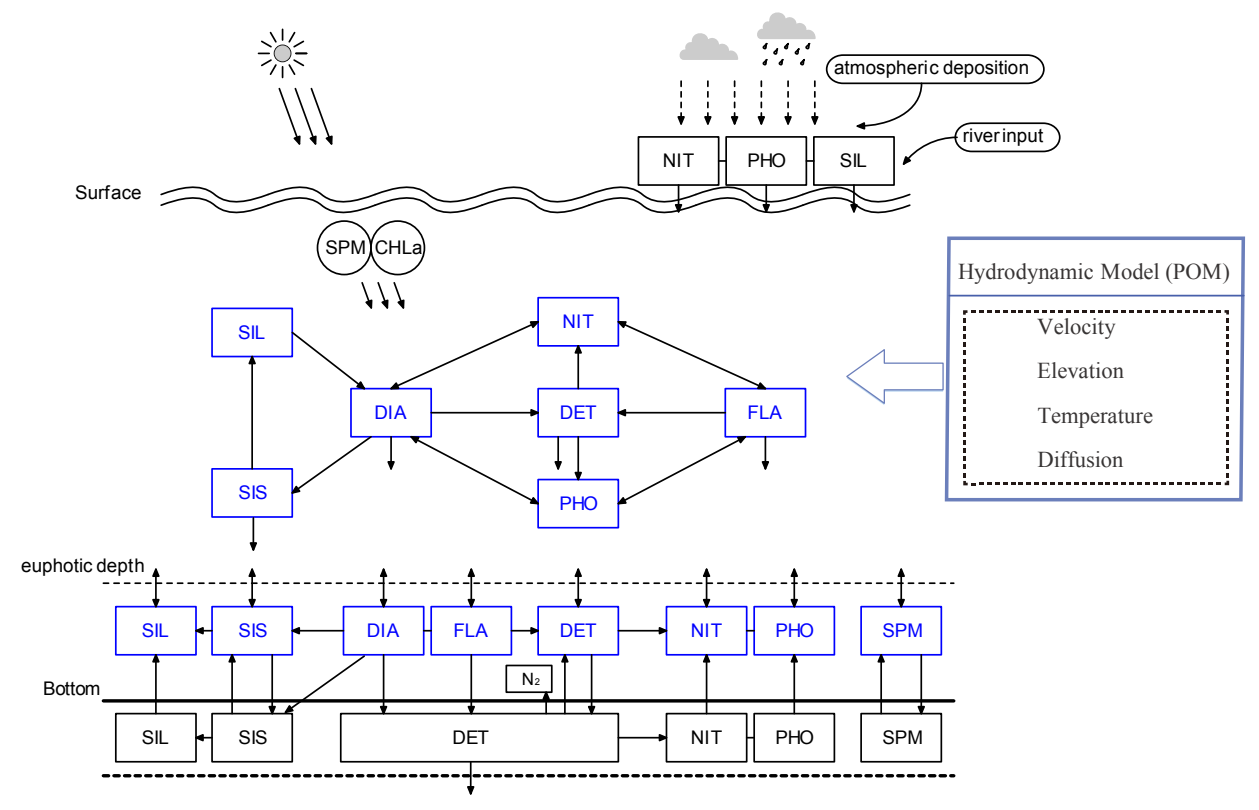

Fig. 2. Schematic illustration of the biophysical model that has a hydrodynamic module and a biological module. The hydrodynamic module is based on the Princeton Ocean Model (POM) (Mellor, 2003). The biological module includes three elements of nutrients (dissolved inorganic nitrogen (DIN), dissolved inorganic phosphorus (DIP), and silicate (SIL)), two types of phytoplankton (diatoms (DIA) and flagellates (FLA)), and two types of biogenic organic materials (dead organic matter containing nitrogen and phosphorus (DET) and biogenic silica (SIS)). See text for the processes included in this module.

inorganic phosphorus (DIP), and silicate (SIL)), two types of phytoplankton (diatoms (DIA) and flagellates (FLA)), and two types of biogenic organic material (dead organic matter (DET) and biogenic silica (SIS)).

The biological module treats the water column and benthic layer as two individual parts (Fig. 2). Biological processes in the water column include photosynthesis, respiration, and mortality of phytoplankton, and remineralization of detritus, while those in the benthic layer include remineralization, denitrification, resuspension, and burial of detritus. The biological module also includes sinking of phytoplankton and detritus from the sea surface to the benthic layer, diffusion fluxes of nutrients from the benthic layer to the water column, nutrient inputs from rivers, and atmospheric dry and wet deposition of nutrients at the air-sea interface. The equations for the biochemical processes follow those given in Aksnes et al. (1995), Skogen et al. (1995), and Skogen and Søiland (1998). Parameters used in the equations (Table 1) for biochemical processes were based on the values in the literature (Moll, 1998; Skogen and Moll, 2000; Wei et al., 2004), but were adjusted by trial and error.

Because of the high turbidity in the ECS, not only chlorophyll $a$ but also suspended particulate matter (SPM) was used to determine the extinction coefficient of photosynthetically active radiation $(k)$.

$k=k_{0}+k_{1} C_{\mathrm{SPM}}+k_{2} \int_{0}^{z} C_{\mathrm{CHLa}}(z) d z$
Here, $k_{0}$ is the coefficient for clear water, $k_{1}$ is the light attenuation due to SPM absorption, $C_{\mathrm{SPM}}$ is the satellite derived monthly SPM concentration (Wang and Jiang, 2008), $k_{2}$ is the self-shading by chlorophyll $a, C_{\mathrm{CHLa}}(z)$ is the profile of simulated chlorophyll $a$. The values of these parameters are listed in Table 1.

The reason we included three nutrient elements is because any of them can limit primary production in the ECS. The traditional idea is that primary production in the ECS is limited by DIN or DIP, depending on where observations are made (Wong et al., 1998; Liu et al., 2003). Recently, silicate was also suggested as a potential limiting nutrient (Chen et al., 2004; Zhang et al., 2007b).

Zooplankton are important in the ECS but were not included in our biological module. If we directly include zooplankton in our model, we need to consider two sizes of zooplankton (micro-zooplankton and macro-zooplankton) corresponding to the two sizes of phytoplankton. However, we did not find sufficient field data on the micro-zooplankton and macro-zooplankton in our study area. This is the primary reason why we did not directly include zooplankton. On the other hand, the inclusion of zooplankton may introduce additional biological processes and parameters. As we mentioned previously, our objective is to examine the onshore nutrient flux and its effects on primary production over the shelf. To this end, zooplankton grazing on phytoplankton can be partly taken into account by increasing the mortality rate of phytoplankton in our model. Furthermore, the 
Table 1. Parameters used in the model simulation for the East China Sea.

\begin{tabular}{lll}
\hline Parameter description & Value & Unit \\
\hline Diatom production maximum at 0 degree Celsius & 1.33 & $1 / \mathrm{day}$ \\
Temperature dependent maximum production for diatoms & 0.063 & $1 / \mathrm{deg}$ \\
Flagellate production maximum at 0 degree Celsius & 1.05 & $1 / \mathrm{day}$ \\
Temperature dependent maximum production for flagellates & 0.064 & $1 / \mathrm{deg}$ \\
Respiration rate at 0 degree Celsius & 0.061 & $1 / \mathrm{day}$ \\
Respiration rate temperature dependence & 0.064 & $1 / \mathrm{deg}$ \\
Phytoplankton death rate & 0.123 & $1 / \mathrm{day}$ \\
Rate of decomposition of detritus & 0.011 & $1 / \mathrm{day}$ \\
Photosynthetic active irradiance & 0.4 & $/$ \\
Chlorophyll $a$ light extinction coefficient & 0.0138 & $\mathrm{~m} / \mathrm{mgCHLa}$ \\
Extinction due to clean water & 0.04 & $1 / \mathrm{m}$ \\
Extinction due to SPM & 0.032 & $\mathrm{~m} / \mathrm{g}$ \\
Fraction of phosphate and nitrate in a cell & 0.138 & $\mathrm{mgP} / \mathrm{mgN}$ \\
Fraction of silicate and nitrate in a cell & 1.75 & $\mathrm{mgSi} / \mathrm{mgN}^{2}$ \\
Fraction of nitrate and Chlorophyll $a$ in a cell & $8 \sim 11$ & $\mathrm{mgN} / \mathrm{mgCHLa}^{2}$ \\
Half saturation constant of nitrogen for flagellates & 1.2 & $\mathrm{mmolN} / \mathrm{m}^{3}$ \\
Half saturation constant of phosphate for flagellates & 0.09 & $\mathrm{mmolP} / \mathrm{m}^{3}$ \\
Optimum light intensity for flagellates & 60 & $\mathrm{~W} / \mathrm{m}^{2}$ \\
Half saturation constant of nitrogen for diatoms & 1.8 & $\mathrm{mmolN} / \mathrm{m}^{3}$ \\
Half saturation constant of phosphate for diatoms & 0.115 & $\mathrm{mmolP} / \mathrm{m}^{3}$ \\
Half saturation constant of silicate for diatoms & 1.0 & $\mathrm{mmolSi} / \mathrm{m}^{3}$ \\
Optimum light intensity for diatoms & 90 & $\mathrm{~W} / \mathrm{m}^{2}$ \\
Reference temperature for nutrient half saturation & 12 & $\mathrm{deg}$ \\
Rate of decomposition of silicate shells & 0.0056 & $1 / \mathrm{day}$ \\
Sinking rate of detritus & 2.0 & $\mathrm{~m} / \mathrm{day}$ \\
Sinking rate of flagellates & 0.25 & $\mathrm{~m} / \mathrm{day}$ \\
Sinking rate of diatoms & $0.3 \sim 2.0$ & $\mathrm{~m} / \mathrm{day}$ \\
Sinking rate of biogenic silica & 2.0 & $\mathrm{~m} / \mathrm{day}$ \\
\hline
\end{tabular}

contribution of nutrients to primary production can be considered as a bottom-up issue in a low trophic-level ecosystem, for which the NPD type model used here is suitable (Valiela, 1995; Sarmiento and Gruber, 2006).

The model domain covers the Bohai Sea, Yellow Sea and ECS with an open boundary along the southern and eastern boundaries (Fig. 1). With the objective of reproducing seasonal variation, the hydrodynamic module was driven by monthly river runoff, monthly heat flux, monthly evaporation and precipitation rates, and monthly ocean currents at the open boundary. During model integration, the monthly data were linearly interpolated to every time step. The tidal currents were specified at the open boundary as described by Wang et al. (2008). A regression relation with 9 coefficients (annual mean, every two harmonic constants for the annual period, for the semi-annual period, for the 4 month period, and for the 3 month period, respectively) in the Scatterometer Climatology of Ocean Winds (Risien and Chelton, 2008) was used to describe the wind fields at every time step. In order to reproduce the seasonal variations of nutrients and chlorophyll $a$, the same monthly conditions were prescribed at river mouths, at the open boundary and at the air-sea interface for the biological module.

Calculation was started with an initial condition in winter and was spun up for two years; the model results from the third year were then analyzed. The initial conditions for the three nutrient elements were given by referring to Chen (2009). It is necessary to note that using the initial conditions from the World Ocean Atlas 2005 (WOA2005) (Garcia et al., 2006a, b) or from the Marine Atlas of Bohai Sea, Yellow Sea, East China Sea, Chemistry (Wang, 1991) did not change the results much, indicating the strong dependence of the model results on the open boundary conditions, which were from WOA2005. Runoffs from the ten major rivers (Fig. 1) were taken from the Marine Atlas of Bohai Sea, Yellow Sea, East China Sea, Hydrology (Chen, 1992). The concentrations of nutrients in rivers and the fluxes for atmospheric dry and wet deposition of nutrients were obtained from published data (Zhang, 1996; Liu et al., 2009; Wan et al., 2002; Zhang et al., 2007a). Solar radiation was calculated using the model given by Dobson and Smith (1988) and cloud cover data was from the NCEP/NCAR reanalysis (Kalnay et al., 1996). Validation 

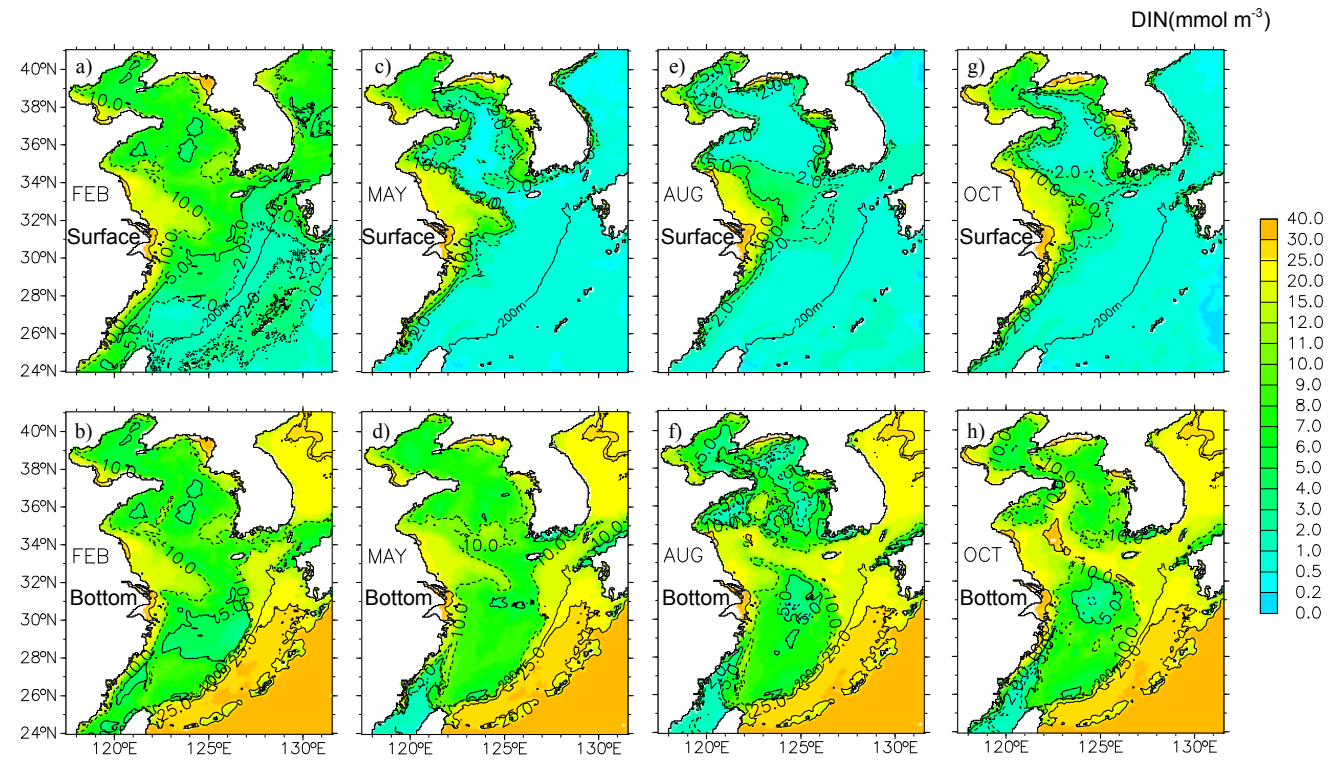

Fig. 3. Horizontal distribution of simulated DIN $\left(\mathrm{mmol} \mathrm{m}^{-3}\right)$ at the surface $(2 \mathrm{~m} \mathrm{depth})$ and bottom layer (the deepest sigma layer) in four seasons.

data for nutrients and chlorophyll $a$ were from the Japan Meteorological Agency's (JMA) monitoring data around the shelf break and along the PN line (see Fig. 1 for its position) in the ECS.

\section{Results}

\subsection{Temporal and spatial variations of nutrients and chlorophyll $a$}

For a comparison with the observations (Chen, 2009), the horizontal distribution of DIN, as an example of simulated nutrients, in the surface and bottom layers for four seasons is shown in Fig. 3. The corresponding figures, based on observations, in February and August from Chen (2009) are given in Fig. 4.

In winter, the surface DIN concentration was high along the western coast of the ECS and the eastern coast of the Yellow Sea, but was low in the central Yellow Sea and the northwestern coast of the Yellow Sea (Fig. 3a). The lowest DIN concentrations were found along and outside of the shelf break where nutrient-poor Kuroshio surface water is found. Because of strong wind stirring in winter and tidal mixing, the DIN in the bottom layer of the Yellow Sea and the inner shelf of ECS (Fig. 3b) displayed a similar distribution to that in the surface layer (Fig. 3a). However, in the bottom layer of the middle and outer shelves, the DIN concentration was higher than that of the surface layer. Although these features can be confirmed in Fig. 4, we still can find inconsistencies between the model and observational results. For example, the concentration of DIN in winter in
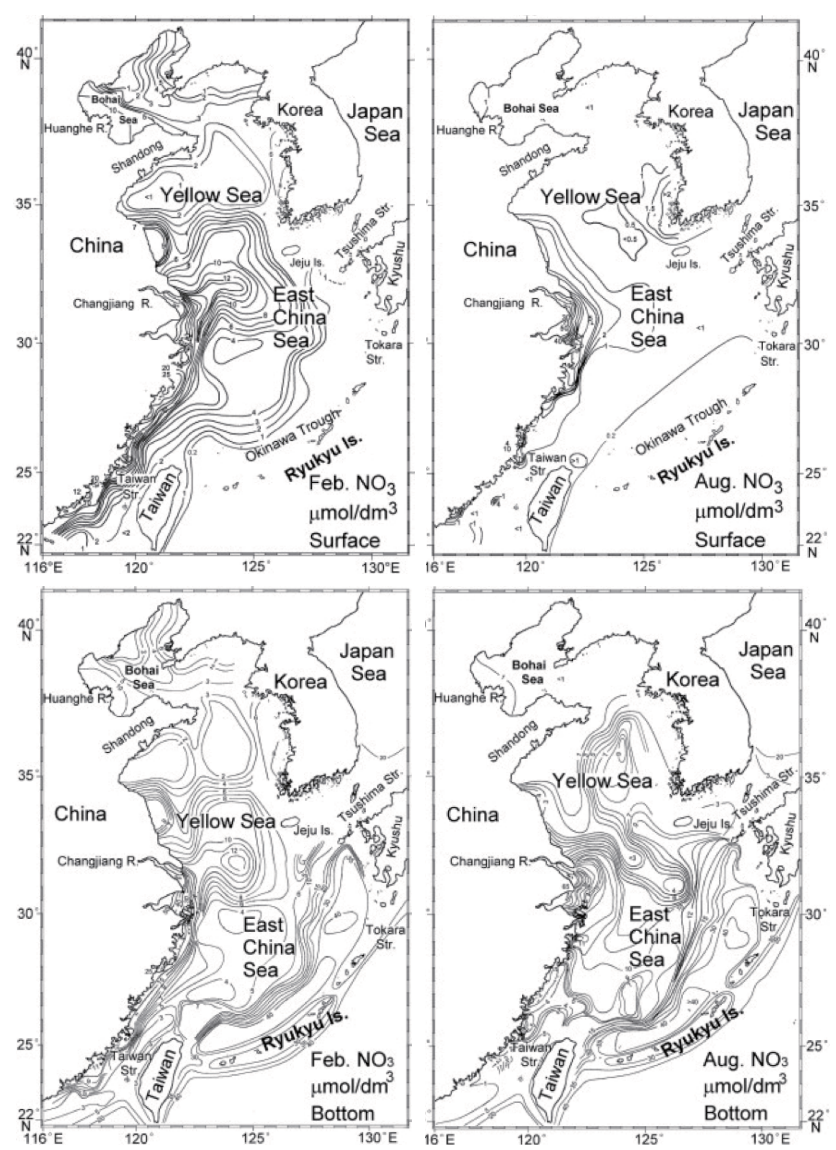

Fig. 4. Surface and bottom nitrate concentrations in February and August, taken from Chen (2009). 
the Yellow Sea is higher in the model results (Fig. 3) than in observational results (Fig. 4). The physical explanation for such overestimation was a northward shift in the position of Changjiang diluted water due to the usage of climatological wind fields. The associated biochemical processes could be related to the satellite SPM concentrations in region offshore of the Changjiang river mouth that were probably overestimated. The overestimation of SPM induced a lower underwater light intensity and therefore a lower production rate of phytoplankton, which resulted in a somewhat higher concentration of nutrients in the Changjiang diluted water.

In spring, surface DIN concentrations were similar to levels observed in winter along the western coast of the ECS, but they decreased sharply in the central Yellow Sea and from the middle to outer shelf of the ECS (Fig. 3c). In the bottom layer (Fig. 3d), the DIN concentration decreased markedly in the Taiwan Strait but increased from north Taiwan to the middle shelf south of $30^{\circ} \mathrm{N}$; the bottom DIN also increased in the central Yellow Sea. The decrease in surface nutrients can be easily related to the intensification of biological activity and the reduction of the nutrient supply from the bottom layer to the surface layer in spring. With increasing solar radiation and weakening of winds from winter to spring, stratification in the ECS and Yellow Sea has developed by May. Thermal stratification reduced the upward transport of nutrients from the bottom layer to the surface layer. At the same time, the dissolved nutrients released by remineralization of sinking particulate organic matter in the bottom layer are kept there, causing an increase in DIN. In addition, the intensification of the Kuroshio subsurface water intrusion in spring may also influence the increase of DIN in the bottom layer over the middle and outer shelves (Jacobs et al., 2000).

In summer, the dispersal of nutrient-poor water (DIN $<1 \mathrm{mmol} \mathrm{m}^{-3}$ ) from the central area to coastal areas in the Yellow Sea and the offshore spreading of nutrient-rich water (DIN $>1 \mathrm{mmol} \mathrm{m}^{-3}$ ) from the Changjiang estuary toward Jeju Island in the ECS (Fig. 3e) caused a significant change in the surface layer. This feature is also found in Fig. 4. The reduction of surface nutrients in the Yellow Sea can be easily explained by the intensification of stratification in summer, while the mechanism of long distance offshore transport of nutrients from the Changjiang estuary has been given by Isobe and Matsuno (2008). In the bottom layer, nutrients increased in the northern shelf of the ECS (southwest of Jeju Island) but decreased in the offshore area of the Changjiang estuary and the northern part of the Yellow Sea (Fig. 3e and f). According to Fig. 4, the nutrients within the bottom layer of the ECS shelf have higher concentrations in summer than in winter, which can be found in model results too.

In autumn, the concentration of surface DIN was low in the central Yellow Sea and over the middle and outer shelves of the ECS, with increased levels in the western and eastern coasts of the Yellow Sea (Fig. 3g). In the bottom layer (Fig. 3h), nutrient-rich water was found from the central Yellow Sea to the northern shelf of the ECS, and as far as the shelf break, indicating a possible route of nutrient supply from Kuroshio subsurface water.

In general, not only nutrients but also light intensity, water temperature and stratification controlled phytoplankton growth in the surface water. With increasing surface temperatures in spring, the water column became stable, and high surface concentrations of chlorophyll $a$ initially appeared in the central region of the Yellow Sea during April (Fig. 5). From April to September, the high-density surface chlorophyll $a$ area moved gradually to the coastal waters of the Yellow Sea. Meanwhile, a band of high-density surface chlorophyll $a$ was maintained from the western Yellow Sea to the offshore region of the Changjiang estuary. In autumn (e.g. October) slightly higher chlorophyll $a$ values were found again in the central region of the Yellow Sea. In the area from the Changjiang estuary to the ECS shelf break, a highdensity surface chlorophyll $a$ area appeared first at the outer shelf (northeast of Taiwan) in winter (e.g., January), then gradually moved to the inner shelf from spring to summer, and remained offshore of the Changjiang estuary in autumn (e.g. October). The Changjiang River provides not only nutrients but also suspended sediments to the ECS. The reason for the relatively low chlorophyll $a$ levels in close proximity to the estuary is the high turbidity caused by the amount of suspended sediments from the Changjiang River that significantly weakened subsurface light intensity.

\subsection{Vertical distribution of chlorophyll $a$ and nutrients along a transect across the shelf break}

There is an established transect in the ECS, called the PN line, where JMA has conducted hydrographic surveys for more than 40 years. Usually, the survey is carried out four times a year, once per season. Here we first describe the common features of nutrients and chlorophyll $a$ in the observational and model results (Figs. 6 and 7), then address the possible causes for the differences between the observational and model results. The observations are for nutrients (represented by DIN) and chlorophyll $a$ averaged in each season from 1965 to 2004, whereas the model results are the same variables but with monthly means from February, May, August and October, representing winter, spring, summer and autumn, respectively.

In winter, both nutrients and chlorophyll $a$ were vertically homogenous over the shelf due to intensive mixing. Nutrient concentrations were higher in the inshore side than the offshore side in the upper layer (water depth $<100 \mathrm{~m}$ ). The highest nutrient concentrations were found in the lower layer (water depth $>100 \mathrm{~m}$ ) from the shelf break to the open ocean, and they are expected to be an important source of nutrients to the upper layer and middle shelf. Chlorophyll $a$ concentrations were high in the surface layer from the shelf break to the open ocean.

In spring, nutrients in the surface layer were quickly depleted with the advent of phytoplankton growth. This 

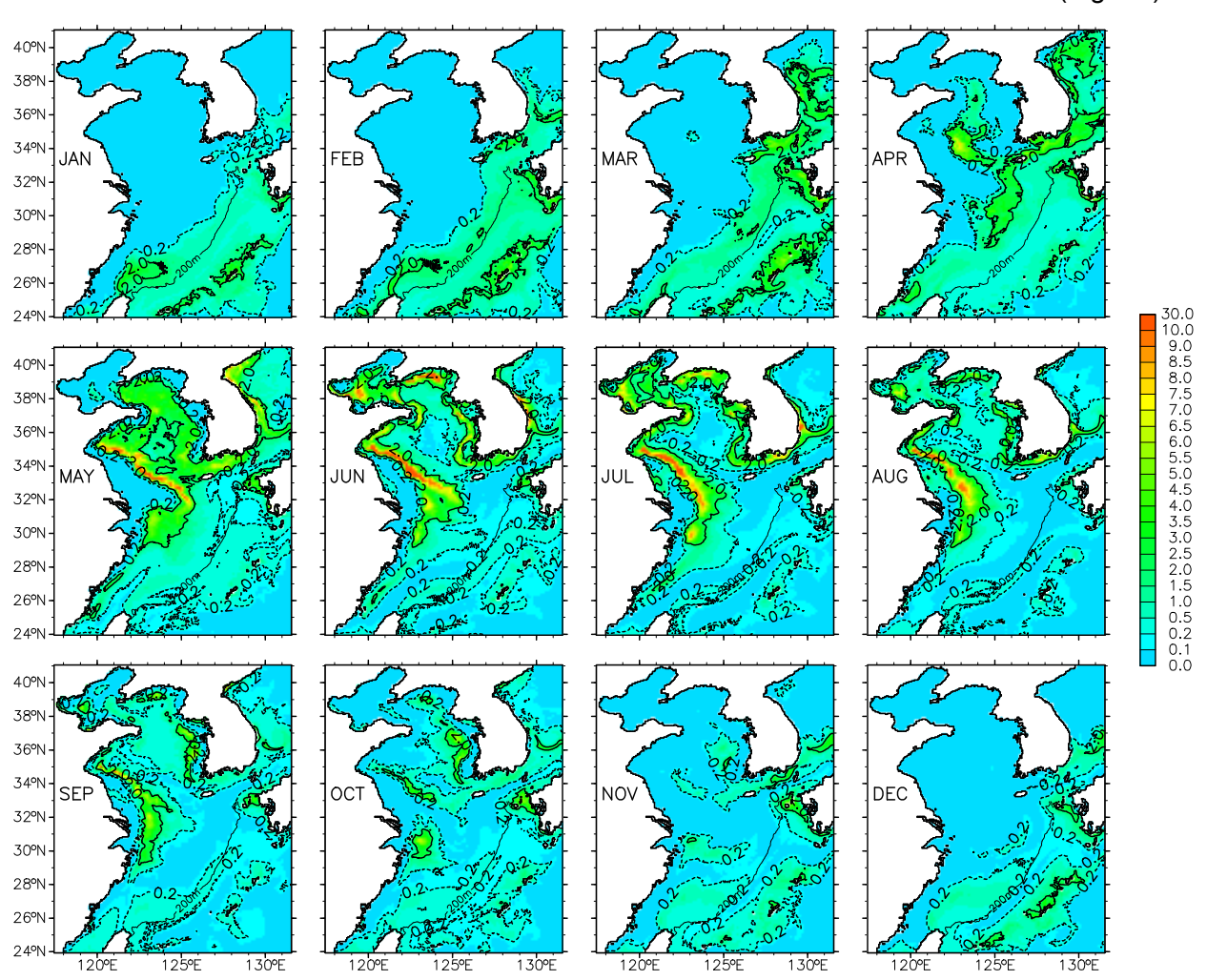

Fig. 5. Horizontal distribution of simulated chlorophyll $a\left(\mathrm{mg} \mathrm{m}^{-3}\right)$ at the surface layer $(2 \mathrm{~m}$ depth $)$ in 12 months.

occurred from the inshore side of the shelf to the shelf break, with the maximum chlorophyll $a$ concentration occurring in the surface layer or shallow subsurface layer. With changes in phytoplankton production, the euphotic zone became shallower from the inshore side of the shelf to the shelf break, but became deep farther offshore. In the bottom layer, nutrientrich water could be identified from the inshore side of the shelf to the shelf break. From the depth of the euphotic zone and the distribution of nutrients, it can be deduced that the nutrient-rich bottom water contributes greatly to phytoplankton growth.

In summer, the concentration of surface nutrients decreased and limited the growth of phytoplankton. With a decrease in surface phytoplankton, the euphotic zone deepened and subsurface phytoplankton could utilize nutrients in the deeper layer. Consequently, the subsurface chlorophyll $a$ maximum over the shelf appeared deeper in summer than in spring and the concentration of nutrients in the bottom layer decreased slightly.

In autumn, the concentration of surface nutrients recovered slightly due to the intensification of surface mixing. Chlorophyll $a$ still had a high concentration in the middle layer, indicating a persistent contribution of nutrient-rich bottom water to subsurface primary production from spring to autumn.
Although we can confirm the above features from both the observational and model results, differences were also apparent. For example, the high chlorophyll $a$ concentration observed on the inshore side of the shelf in winter and autumn was not reproduced by the model. The high chlorophyll $a$ concentration at the open ocean side was always found in model results but could not be confirmed in the observational data. In addition, the concentration of chlorophyll $a$ in the subsurface layer over the shelf in summer and the concentration of nutrients below the subsurface layer from the shelf break to the open ocean side were generally higher in the model results than in the observational data. These fundamental differences may have been caused by either incomplete observational data specified along the open boundary or the incomplete structure of our biological module. Improvement of the former depends on the extent of data collection east of Taiwan and within the Taiwan Strait, while the latter can be addressed by adding biological components such as zooplankton, or by including additional processes such as the microbial loop. Nevertheless, continuous effort to improve model performance is necessary in the future.

Since we want to evaluate the onshore fluxes of nutrients across the shelf break, we need to confirm that the inconsistency between the model and observational results has no serious influence on this evaluation. In Fig. 8, we plot all 


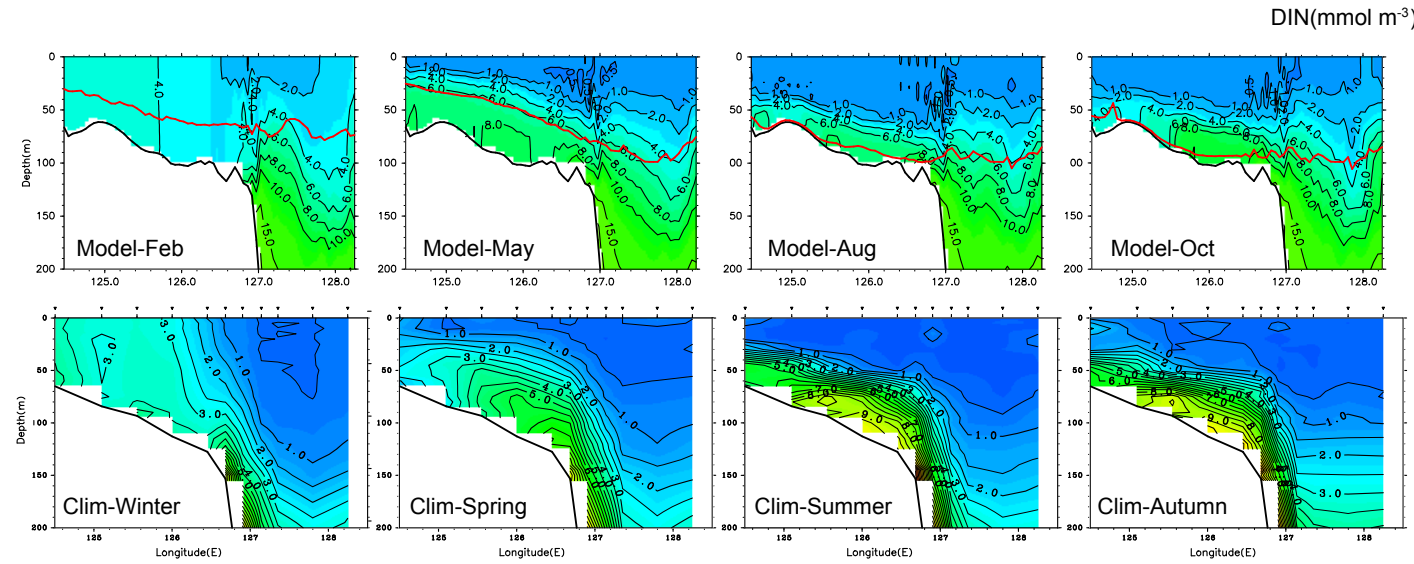

Fig. 6. Simulated (upper panels) and observed (lower panels) distributions of DIN ( $\mathrm{mmol} \mathrm{m}^{-3}$ ) along the PN line in four seasons. Red lines in the upper panels denote euphotic depth.
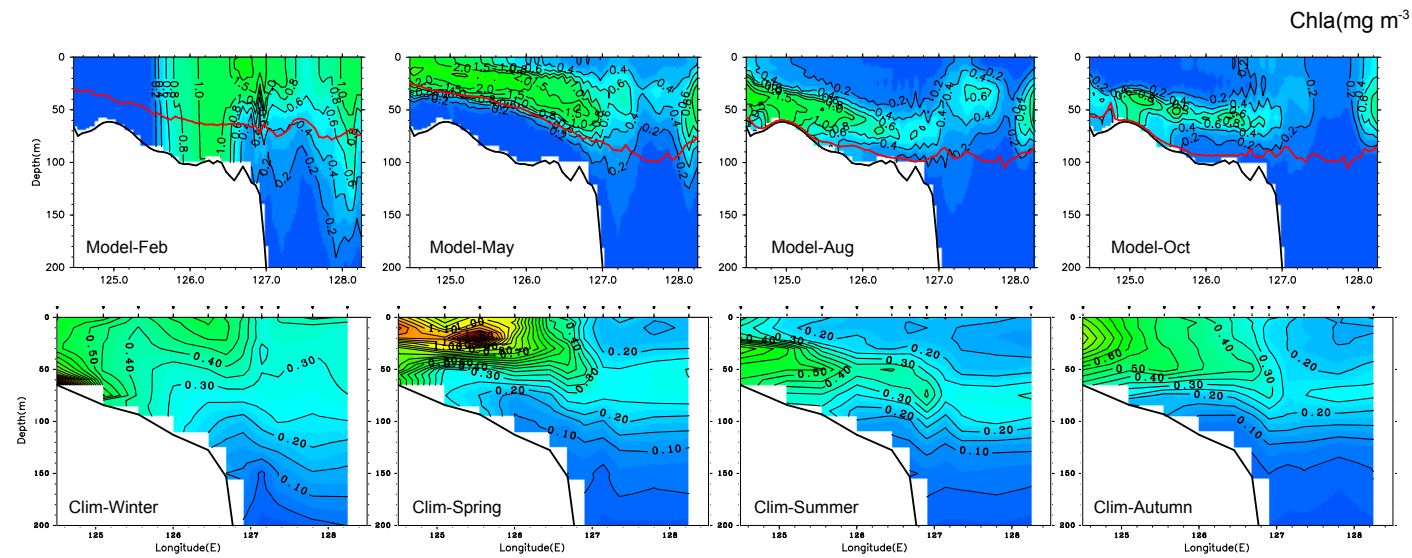

Fig. 7. The same as Fig. 6 but for chlorophyll $a\left(\mathrm{mg} \mathrm{m}^{-3}\right)$.

the available DIN and DIP data from JMA routine observations around the shelf break (the station depth was between 150 and $250 \mathrm{~m}$, see Fig. 1 for position of stations) and the corresponding model results at the same places and for the same month and day as the observations. The observed nutrients around the shelf break show large variability and the model results represent this variability with an acceptable precision, considering that the model was driven by climatological forcing. Based on this comparison, the inconsistency between model and observational results that we previously mentioned should have no serious influence on the calculation of nutrient fluxes that depend only on the simulated nutrient concentration along the $200-\mathrm{m}$ isobath, more specifically, the line given in Fig. 1.

\subsection{Seasonal and spatial variations in onshore fluxes of nutrients across the shelf break}

Using flow velocity and nutrient concentrations from the model, we can calculate the onshore flux of water and nu- trients across the shelf break of the ECS (defined by the 200$\mathrm{m}$ isobath in Fig. 1). The volume transport of onshore water $\left(V H_{+}^{i}\right)$ and offshore water $\left(V H_{-}^{i}\right)$ at the $i$ th grid point along the $200-\mathrm{m}$ isobath as well as their corresponding nutrient fluxes $\left(F H_{+}^{i}\right.$ and $\left.F H_{-}^{i}\right)$ were calculated as follows:

$$
\begin{aligned}
& V H_{+}^{i}=\sum_{k=1, M} u_{+}^{i, k} d z^{i, k} d x^{i} \\
& V H_{-}^{i}=\sum_{k=1, M} u_{-}^{i, k} d z^{i, k} d x^{i} \\
& F H_{+}^{i}=\sum_{k=1, M} C^{i, k} u_{+}^{i, k} d z^{i, k} d x^{i} \\
& F H_{-}^{i}=\sum_{k=1, M} C^{i, k} u_{-}^{i, k} d z^{i, k} d x^{i}
\end{aligned}
$$

Here, $u$ denotes onshore or offshore velocity; $d x$ and $d z$ are horizontal and vertical intervals of grid points; $C$ denotes concentration of one nutrient element; subscripts + and - 

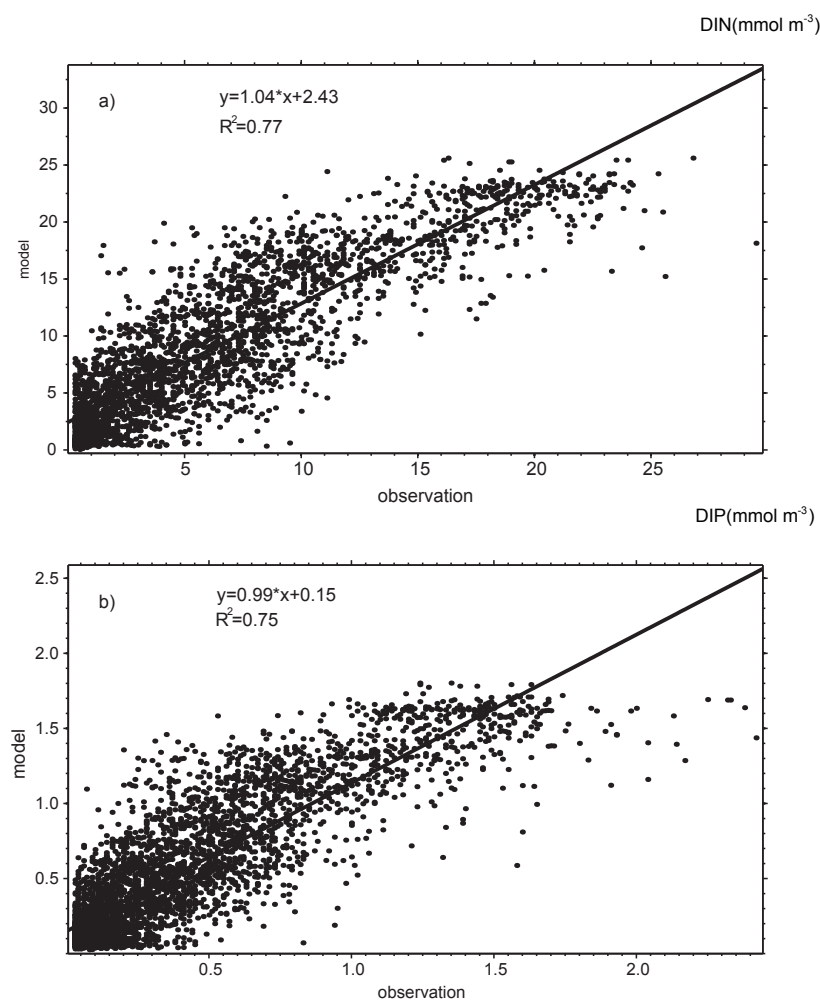

Fig. 8. Scatter plot of all the available (a) DIN and (b) DIP data from routine JMA observations around the shelf break (see Fig. 1 for position of stations) and corresponding model results at the same places in the same month and same day as the observations.

denote onshore velocity and offshore velocity, respectively; superscript $i$ and $k$ are horizontal and vertical indexes for the grid points, respectively; and $M$ is the total grid point number in the vertical direction.

By integrating onshore and offshore fluxes of water and nutrients at each grid point along the 200-m isobath, we obtained the total volume transports of onshore water $\left(\mathrm{Vol}_{+}\right)$ and offshore water $\left(\mathrm{Vol}_{-}\right)$as well as the total nutrient fluxes transported by the onshore water $\left(F_{+}\right)$and by the offshore water $\left(F_{-}\right)$across the shelf break.

$\mathrm{Vol}_{+}=\sum_{i=1, N} V H_{+}^{i}, \mathrm{Vol}_{-}=\sum_{i=1, N} V H_{-}^{i}$,

$F_{+}=\sum_{i=1, N} F H_{+}^{i}, F_{-}=\sum_{i=1, N} F H_{-}^{i}$.

Here, $N$ is the total number of grid points in the horizontal direction. In addition, the mean concentration within the onshore water $\left(C_{+}=F_{+} / \mathrm{Vol}_{+}\right)$, and that within the offshore water $\left(C_{-}=F_{-} / \mathrm{Vol}_{-}\right)$were also calculated.

Since the main stream of the Kuroshio flows along the shelf break, the flux across the shelf break in the ECS is also called the Kuroshio onshore flux. Because of this, the calculated nutrient fluxes $\left(F_{+}+F_{-}\right)$can be compared to previous estimates of nutrient flux by Chen and Wang (1999) and Zhang et al. (2007b) who used a box model for the ECS shelf. For this reason, we first present total fluxes of water and nutrients across the shelf break and then examine their horizontal distributions along the 200-m isobath, which cannot be given by a box model.

The volume of the Kuroshio onshore flux ( $\left.\mathrm{Vol}_{+}+\mathrm{Vol}_{-}\right)$ reached a minimum of $\sim 0.5 \mathrm{~Sv}\left(1 \mathrm{~Sv}=10^{6} \mathrm{~m}^{3} \mathrm{~s}^{-1}\right)$ in June and a maximum of $\sim 3 \mathrm{~Sv}$ in November, displaying significant seasonal variations (Fig. 9). The annual mean volume of the Kuroshio onshore flux was estimated to be $1.53 \mathrm{~Sv}$ with a standard deviation of $0.97 \mathrm{~Sv}$. All are consistent with the results calculated by a previous version of the hydrodynamic module (Guo et al., 2006), in which tidal currents were excluded and river discharge was not explicitly included.

The Kuroshio onshore flux $\left(F_{+}+F_{-}\right)$of DIN and DIP (Fig. 9) generally followed the seasonal variation in volume flux with the exception of from March to June. The fluxes of DIN and DIP reached a minimum in March, not in June when the minimum volume flux occurred. Afterward, they increased gradually until November when they reached maximums of $\sim 16.0 \mathrm{kmols}^{-1}$ for DIN and $\sim 1.1 \mathrm{kmols}^{-1}$ for DIP; this was the same as for the volume flux. The Kuroshio onshore flux of silicate showed different seasonal variation from those of volume, DIN and DIP. Silicate displayed a minimum in March as seen with DIN and DIP, but thereafter it increased erratically. Before November when silicate reached its maximum, we observed three peaks in the Kuroshio onshore flux of silicate.

The annual mean of the Kuroshio onshore flux was $9.4 \mathrm{kmols}^{-1}$ for DIN, $0.7 \mathrm{kmols}^{-1}$ for DIP, and $18.2 \mathrm{kmols}^{-1}$ for silicate; the standard deviation was $4.6 \mathrm{kmols}^{-1}$ for DIN, $0.4 \mathrm{kmols}^{-1}$ for DIP, and $12.0 \mathrm{kmols}^{-1}$ for silicate. The annual mean values given here are on the same order as those estimated by the box models: $10.7 \mathrm{kmols}^{-1}$ for DIN, and $0.34 \mathrm{kmols}^{-1}$ for DIP from Chen and Wang (1999); $9.7 \mathrm{kmols}^{-1}$ for DIN, $0.65 \mathrm{kmols}^{-1}$ for DIP, $14.95 \mathrm{kmols}^{-1}$ for silicate from Zhang et al. (2007b).

The seasonal variations in the Kuroshio onshore flux of DIN, DIP and silicate (Fig. 9) is essentially consistent with those estimated by Zhang et al. (2007b), who showed a double input of DIN and DIP and a triple input of silicate from the Kuroshio to the shelf from summer to winter. The reason why the total nutrient fluxes $\left(F_{+}+F_{-}=\mathrm{Vol}_{+} C_{+}+\mathrm{Vol}_{-} C_{-}\right)$ did not exactly follow the seasonal variation in total volume flux $\left(\mathrm{Vol}_{+}+\mathrm{Vol}_{-}\right)$is because the nutrient concentration in the inflow water $\left(C_{+}\right)$was different from that in the outflow water $\left(C_{-}\right)$. The inflow volume flux $\left(\mathrm{Vol}_{+}\right)$was always larger than the outflow volume flux $\left(\mathrm{Vol}_{-}\right)$throughout the year (Fig. 10a). However, the mean DIN concentration $\left(C_{+}\right)$in the inflow water was smaller (larger) than that in the outflow water $\left(C_{-}\right)$from September to the following March (from April to September) (Fig. 10b). The same thing occurred for the mean concentrations of DIP and silicate in the inflow and outflow water. The difference in the seasonal variations between total onshore flux of nitrate and that of 
Table 2. Monthly mean nitrate concentration and volume transport of inflow and outflow across the 200-m isobath at the areas northeast of Taiwan(NoT) and southwest of Kyushu(SoK). Positive values denote onshore transport.

\begin{tabular}{|c|c|c|c|c|c|c|c|c|}
\hline \multicolumn{5}{|c|}{ mean nitrate concentration $\left(\mathrm{mmol} \mathrm{m}^{-3}\right)$} & \multicolumn{4}{|c|}{ volume transport $(\mathrm{Sv})$} \\
\hline \multirow[t]{2}{*}{ Month } & \multicolumn{2}{|c|}{ NoT } & \multicolumn{2}{|c|}{ SoK } & \multicolumn{2}{|c|}{ NoT } & \multicolumn{2}{|c|}{ SoK } \\
\hline & inflow & outflow & inflow & outflow & inflow & outflow & inflow & outflow \\
\hline 1 & 5.70 & 6.45 & 9.63 & 9.55 & 9.20 & -4.54 & 3.64 & -3.44 \\
\hline 2 & 4.52 & 5.24 & 9.28 & 8.86 & 9.52 & -4.53 & 3.87 & -3.65 \\
\hline 3 & 3.68 & 4.27 & 9.12 & 8.51 & 9.83 & -4.75 & 3.96 & -3.67 \\
\hline 4 & 4.29 & 4.74 & 9.07 & 7.96 & 10.45 & -4.86 & 3.68 & -3.58 \\
\hline 5 & 4.19 & 4.57 & 9.22 & 7.42 & 10.68 & -4.98 & 3.59 & -3.52 \\
\hline 6 & 3.86 & 4.06 & 10.20 & 8.24 & 10.50 & -4.89 & 3.79 & -43.71 \\
\hline 7 & 3.82 & 3.94 & 10.42 & 8.54 & 11.25 & -5.23 & 4.14 & -3.98 \\
\hline 8 & 4.23 & 4.48 & 10.06 & 8.86 & 10.84 & -5.22 & 3.97 & -3.50 \\
\hline 9 & 3.77 & 4.27 & 10.06 & 10.23 & 10.44 & -5.21 & 3.63 & -2.51 \\
\hline 10 & 3.81 & 4.50 & 9.95 & 9.83 & 10.73 & -5.11 & 3.93 & -2.68 \\
\hline 11 & 4.26 & 5.11 & 10.03 & 9.28 & 10.68 & -4.91 & 4.36 & -3.36 \\
\hline 12 & 4.30 & 5.15 & 10.02 & 9.55 & 10.09 & -4.79 & 4.25 & -3.51 \\
\hline
\end{tabular}

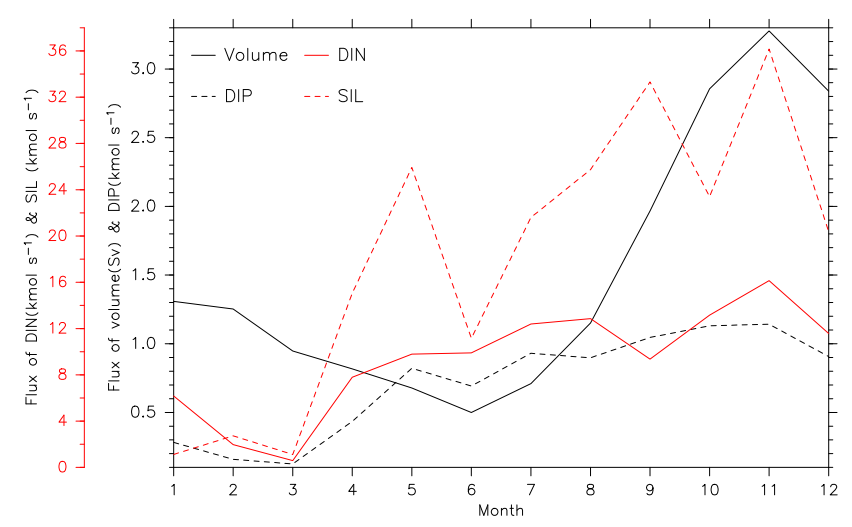

Fig. 9. Monthly onshore flux of volume (Sv) and nutrients $\left(\mathrm{kmol} \mathrm{s}^{-1}\right)$ across the entire $200-\mathrm{m}$ isobath shown in Fig. 1. The positive flux direction is toward the ECS shelf. The black solid line denotes volume, the red solid line DIN, the black dashed line DIP, and the red dashed line SIL.

silicate is caused by the concentration specified at the southern open boundary (Fig. 10c). The silicate concentration has three peaks, inducing three peaks in the onshore silicate flux across the 200-m isobath.

In addition to quantifying the total flux across the shelf break, the model results can also provide a spatial measure of the Kuroshio onshore flux of volume and nutrients along the shelf break (Fig. 11). There were two areas where positive onshore flux was concentrated. One was northeast of Taiwan where the Kuroshio bumps against the shelf break and induces a large onshore flux of volume and nutrients. The integration of the Kuroshio onshore flux northeast of Taiwan (from point 1 to point 6 in Fig. 11) gave values of $5.8 \mathrm{~Sv}$ for volume, $21.1 \mathrm{kmols}^{-1}$ for DIN, $1.8 \mathrm{kmols}^{-1}$ for DIP and
$48.3 \mathrm{kmols}^{-1}$ for silicate. The other was located southwest of Kyushu where the Kuroshio veers toward Tokara Strait and induces a large onshore flux of volume and nutrients. The integration from this area (from point 22 to point 32 in Fig. 11) gave values of $0.5 \mathrm{~Sv}$ for volume, $7.8 \mathrm{kmols}^{-1}$ for DIN, $0.6 \mathrm{kmols}^{-1}$ for DIP and $18.7 \mathrm{kmmols}^{-1}$ for silicate. Along the shelf break between them, the Kuroshio onshore flux of volume and nutrients was generally negative, indicating an offshore transport of water and nutrients. Integration along the $200-\mathrm{m}$ isobath from $\sim 26^{\circ} \mathrm{N}$ to $\sim 29^{\circ} \mathrm{N}$ (point 7 to point 21 in Fig. 11) gave values of $-4.7 \mathrm{~Sv}$ for volume, $-19.7 \mathrm{kmols}^{-1}$ for DIN, $-1.6 \mathrm{kmols}^{-1}$ for DIP and $-48.9 \mathrm{kmols}^{-1}$ for silicate.

When comparing the area northeast of Taiwan and that southwest of Kyushu along 200-m isobath, we note that although the onshore volume transport northeast of Taiwan is about ten times that southwest of Kyushu, the nutrient flux is only about three times different. Again, the nutrient fluxes are not exactly proportional to the volume flux, as in the total volume flux and total nutrient flux across the entire shelf break.

As shown in Fig. 10, the net nutrient flux does not always follow the net water flux in a system with a large water flux exchange because the concentration of nutrients in the inflow water can be different from that in the outflow water. Here, we use nitrate as an example to demonstrate this process. Table 2 presents monthly volume transports for inflow and outflow and monthly nitrate concentrations in the inflow and outflow waters at regions northeast of Taiwan and southwest of Kyushu. The monthly nitrate concentrations in the inflow and outflow waters were calculated in a similar way as those in Fig. 10. According to Table 2, the nitrate concentration in the inflow water is lower (higher) than that in the outflow water at area northeast of Taiwan (southwest 

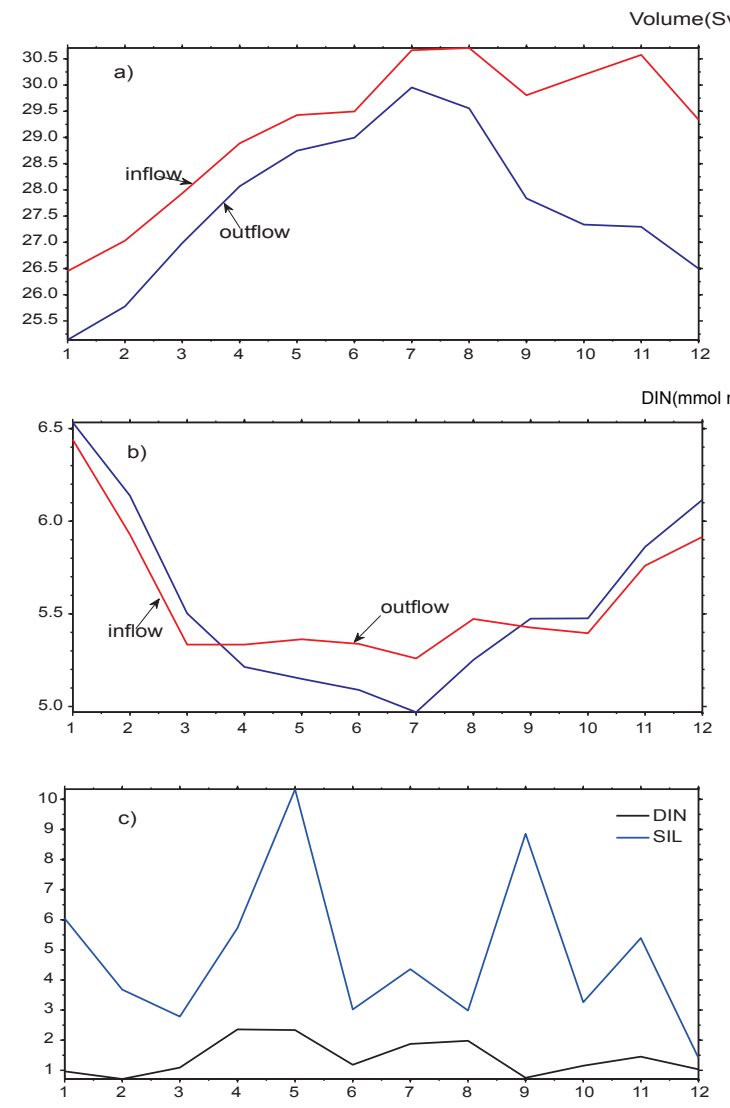

Fig. 10. (a) monthly inflow and outflow volume transports (Sv) across the 200-m isobath. (b) Monthly mean nitrate concentrations $\left(\mathrm{mmol} \mathrm{m}{ }^{-3}\right)$ in the inflow water and outflow water. (c) Seasonal variation of vertically averaged nitrate (black line) and silicate (blue line) concentrations above $200 \mathrm{~m}$ depth at the southern open bound$\operatorname{ary}\left(123^{\circ} \mathrm{E}, 24^{\circ} \mathrm{N}\right)$.

of Kyushu) through a year. On the other hand, the volume transport of the inflow is much larger (a little larger) than that of the outflow at the area northeast of Taiwan (southwest of Kyushu). Consequently, northeast of Taiwan, only the difference in the volume transport of inflow and outflow contributes to the onshore flux of nutrients; the difference in the nutrient concentration of inflow and outflow waters has a negative effect on the onshore flux of nutrients. At the area southwest of Kyushu, both the difference in the volume transport of inflow and outflow and that in the nutrient concentration of inflow and outflow waters have a positive contribution to the onshore flux of nutrients.

\section{Sensitivity experiments on the enrichment of oceanic nutrients}

Although we obtained a positive onshore flux of oceanic nutrients across the shelf break, we still do not know whether these nutrients are involved in photosynthesis over the ECS

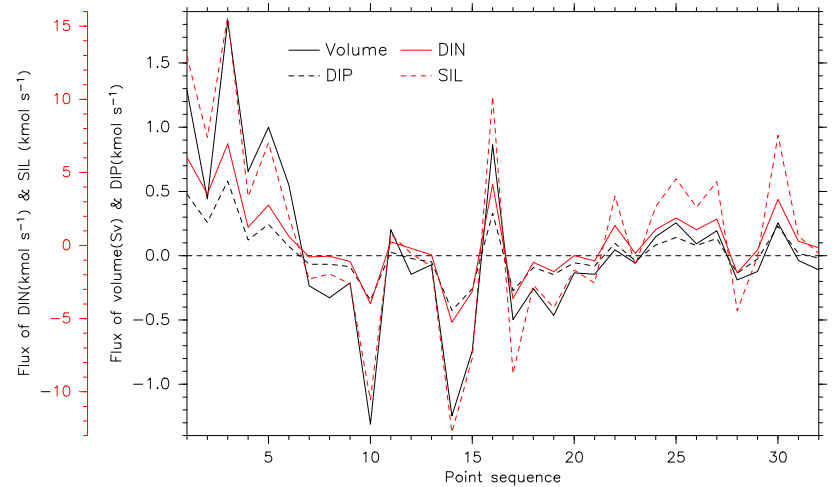

Fig. 11. Spatial distribution along the 200-m isobath of the annual average onshore flux of volume (Sv) and nutrients $\left(\mathrm{kmol} \mathrm{s}^{-1}\right)$. The value at each point is the integrated flux between two points denoted by dots along the 200-m isobath in Fig. 1 . The positive direction is toward the ECS shelf. The black solid line denotes volume, the red solid line DIN, the black dashed line DIP, and the red dashed line SIL.

shelf. As presented in Guo et al. (2006), half of the water through the Tsushima Strait is from the Kuroshio in summer and this ratio increases to $80 \%$ in winter. If the oceanic nutrients that cross the shelf break from the Kuroshio have no opportunity to enter the euphotic zone over the shelf, they only flow over the bottom layer of the shelf and finally pass through the Tsushima Strait without any contribution to the primary production over the ECS shelf.

Direct evaluation of how much the nutrients from the Kuroshio area contribute to the primary production over the ECS shelf must isolate the oceanic nutrients from nutrients from other sources. This isolation is usually problematic in a nonlinear marine ecosystem. Instead of isolation, we used sensitivity experiments, in which we artificially changed the nutrient concentration of the Kuroshio water specified along the lateral boundary of the model and consequently changed the supply of oceanic nutrients across the shelf break from the Kuroshio. The difference in the results between the sensitivity experiments and the simulation presented in Sect. 3 (hereafter called the control experiment) is caused only by the change in the supply of oceanic nutrients across the shelf break, and therefore it can give us some insight to the role of oceanic nutrients in the lower trophic level dynamics of the ECS ecosystem.

We carried out four sensitivity experiments, in which only the concentrations of nutrients (DIN, DIP and silicate) from the sea surface to the bottom along the southern boundary (from Taiwan to $124^{\circ} \mathrm{E}$ ), occupied by Kuroshio water, were multiplied by a constant of $1.1,1.2,1.3$ and 1.4. The other boundary conditions and initial conditions as well as the model integration schedule were the same as those in the control experiment. As a result, the onshore volume flux across the shelf break was the same in all experiments, with 

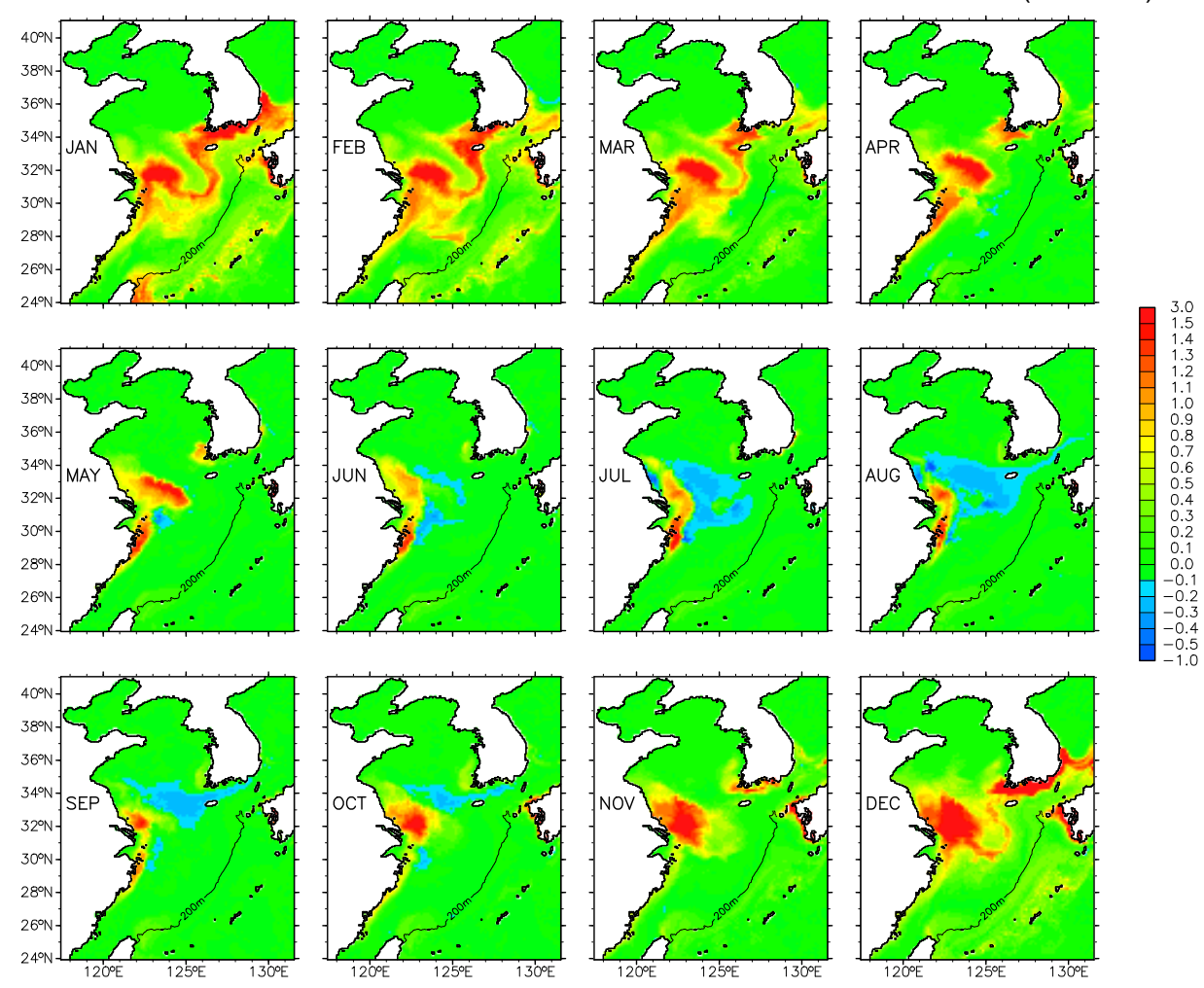

Fig. 12. Anomaly of monthly DIN $\left(\mathrm{mmol} \mathrm{m}^{-3}\right)$ in the surface layer $(2 \mathrm{~m}$ depth) between the sensitivity experiment, in which the oceanic nutrients were enriched by $30 \%$, and the control experiment.

the onshore flux of nutrients artificially increased in the sensitivity experiments.

\subsection{Changes in surface and bottom nutrients and surface chlorophyll $a$ over the shelf of the ECS}

The additional oceanic nutrients (e.g. DIN) in the surface layer appeared mostly offshore of the Changjiang estuary (Fig. 12). In summer (June-August), a positive DIN anomaly (sensitivity experiment - control experiment) was found along the coastal area from $29^{\circ} \mathrm{N}$ to $34^{\circ} \mathrm{N}$, and offshore the DIN anomaly was negative. After September, the area with a positive DIN anomaly was enlarged and extended to the Jeju Strait (the channel between Jeju Island and southern coast of Korea) and farther to the Tsushima Strait in winter (December-February). After March, the positive DIN anomaly gradually retreated to the coastal area. Although not as obvious as offshore of the Changjiang estuary, the additional oceanic nutrients could also be identified over the middle and outer shelves in winter.

The additional oceanic nutrients (e.g. DIN) in the bottom layer over the shelf appeared mostly northeast of Taiwan and southwest of Kyushu (Fig. 13). In the area northeast of Taiwan, a positive anomaly in bottom nutrients can be identified throughout the year. However, its distribution over the shelf enlarged from April to September. In the area southwest of Kyushu, the area with a positive anomaly in bottom nutrients was enlarged from June to September, after which a northwestward branch with a positive nutrient anomaly appeared and reached the Yellow Sea. Because the supply of oceanic nutrients to the middle and inner shelves weakened after October, the high concentration of additional oceanic nutrients in the surface layer offshore of the Changjiang estuary from November to the following April were those that had intruded from April to September.

The response of chlorophyll $a$ in the surface layer to additional oceanic nutrients in winter appeared in the pathway of the Kuroshio, in particular northeast of Taiwan where a local maximum in the chlorophyll $a$ anomaly between the sensitivity and control experiment can be identified (Fig. 14). The additional oceanic nutrients did not produce additional chlorophyll $a$ over the shelf in winter, which can be understood from the low chlorophyll $a$ levels over the shelf in the control experiment (Fig. 5). In other words, primary production over the shelf in winter is not nutrient limited.

From May to September, the positive chlorophyll $a$ anomaly in the surface layer appeared offshore of the Changjiang estuary. A part of the area with the positive chlorophyll $a$ anomaly (Fig. 14) corresponded to the area in the inner shelf with a negative DIN anomaly offshore of the 

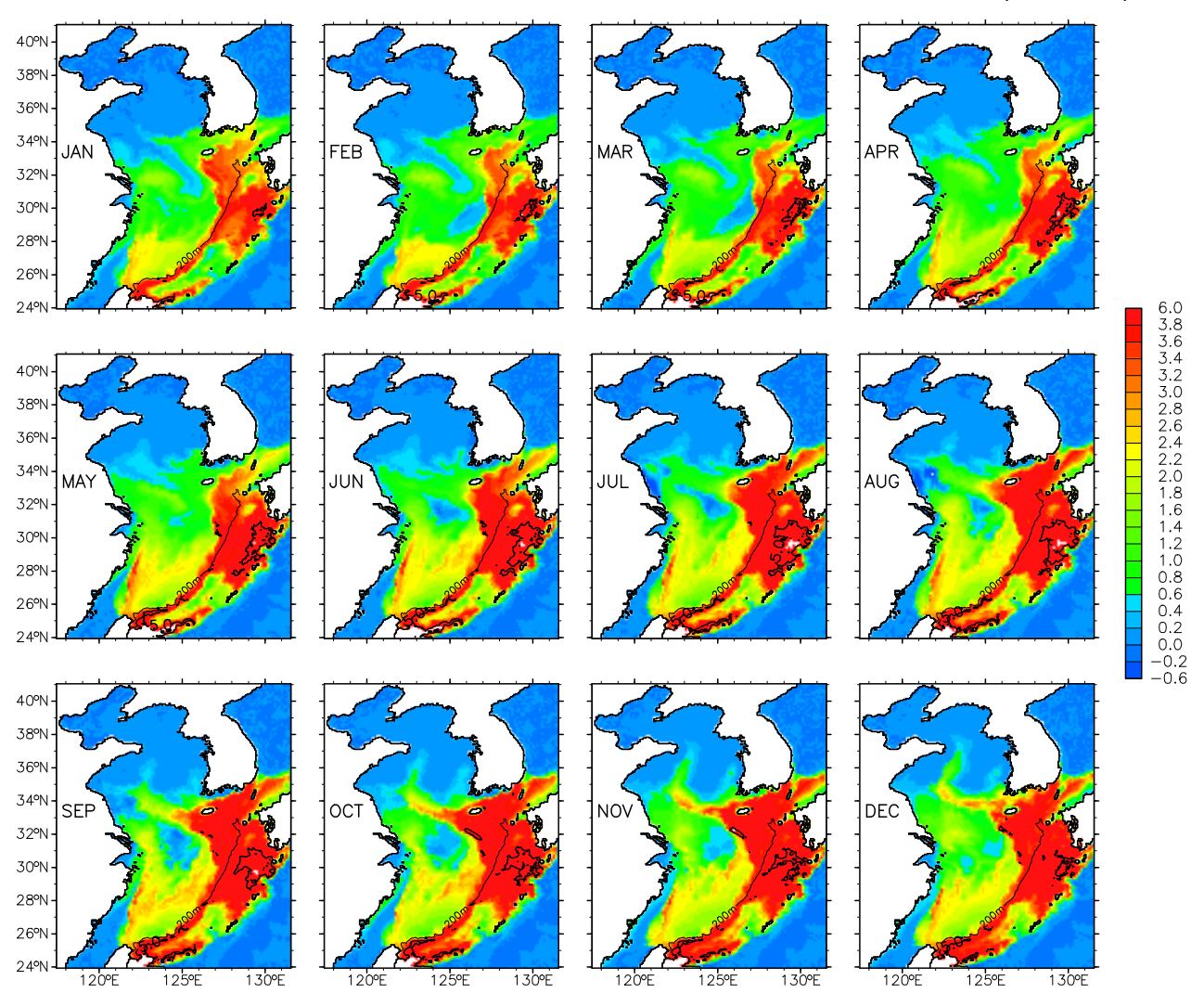

Fig. 13. The same as Fig. 12 but for DIN $\left(\mathrm{mmol} \mathrm{m}^{-3}\right)$ in the bottom layer, defined as the deepest sigma layer. The color range is different from that used in Fig. 12.

Changjiang estuary (Fig. 12). This feature was caused by different ratios of DIN to DIP in the Changjiang River water and in the Kuroshio water and will be discussed in more detail in Sect. 4.3.

\subsection{Changes in subsurface nutrients and chlorophyll $a$ across the shelf of the ECS}

The increment of oceanic nutrients applied in the sensitivity experiments depended on the original concentration in the control experiment, and therefore it was small in the surface layer and large in the subsurface and bottom layers. From January to March, the contours of additional oceanic DIN concentration were horizontally distributed along the PN section (Fig. 15), indicating a small supply of oceanic nutrients to this section in winter. From April to June, the contour of $2 \mathrm{mmol} \mathrm{m}^{-3}$ of additional DIN concentration moved from the shelf break to the middle and inner shelf and remained over the shelf (Fig. 15). An important point in Fig. 15 is that some of the additional oceanic nutrients could enter the euphotic zone.

The additional oceanic nutrients cause an increase in the chlorophyll $a$ concentration in the surface layer in cold months (November to March) and in the subsurface in warm months (June to October) (Fig. 16). April and May appear to be a transition period when the increase in chlorophyll $a$ moves from the surface to subsurface layer. By observing shifts in euphotic depth in Fig. 15, we can infer the consumption of additional oceanic nutrients in the subsurface layer. Therefore, the stable concentration of additional oceanic DIN in the bottom layer over the shelf from June to October (Fig. 15) reflects a balance between the consumption and supply of oceanic nutrients. Similarly, an increase in the additional oceanic DIN at the bottom layer over the shelf in November (Fig. 15) can be caused by either a reduction in phytoplankton growth (Fig. 16) or an increased supply of oceanic nutrients, or both.

\subsection{Changes in nutrient flux across the shelf break and the influence of the elemental ratio of oceanic nutrients on the consumption of nutrients over the shelf}

With an increase in the concentration of oceanic nutrients in the sensitivity experiments, the onshore flux of DIN, DIP and silicate across the $200-\mathrm{m}$ isobath generally increased in 

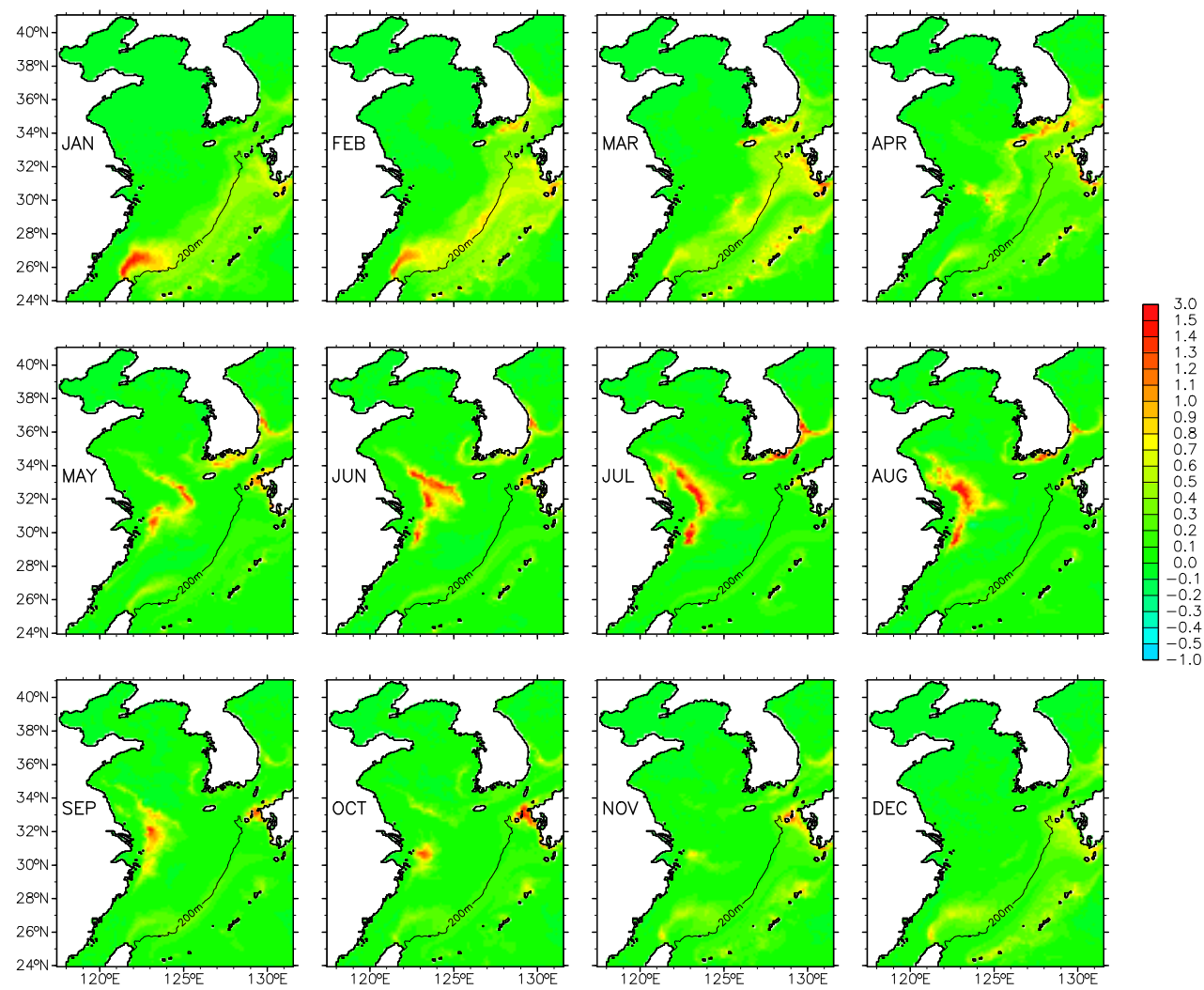

Fig. 14. The same as Fig. 12 but for chlorophyll $a\left(\mathrm{mg} \mathrm{m}^{-3}\right)$ in the surface layer.
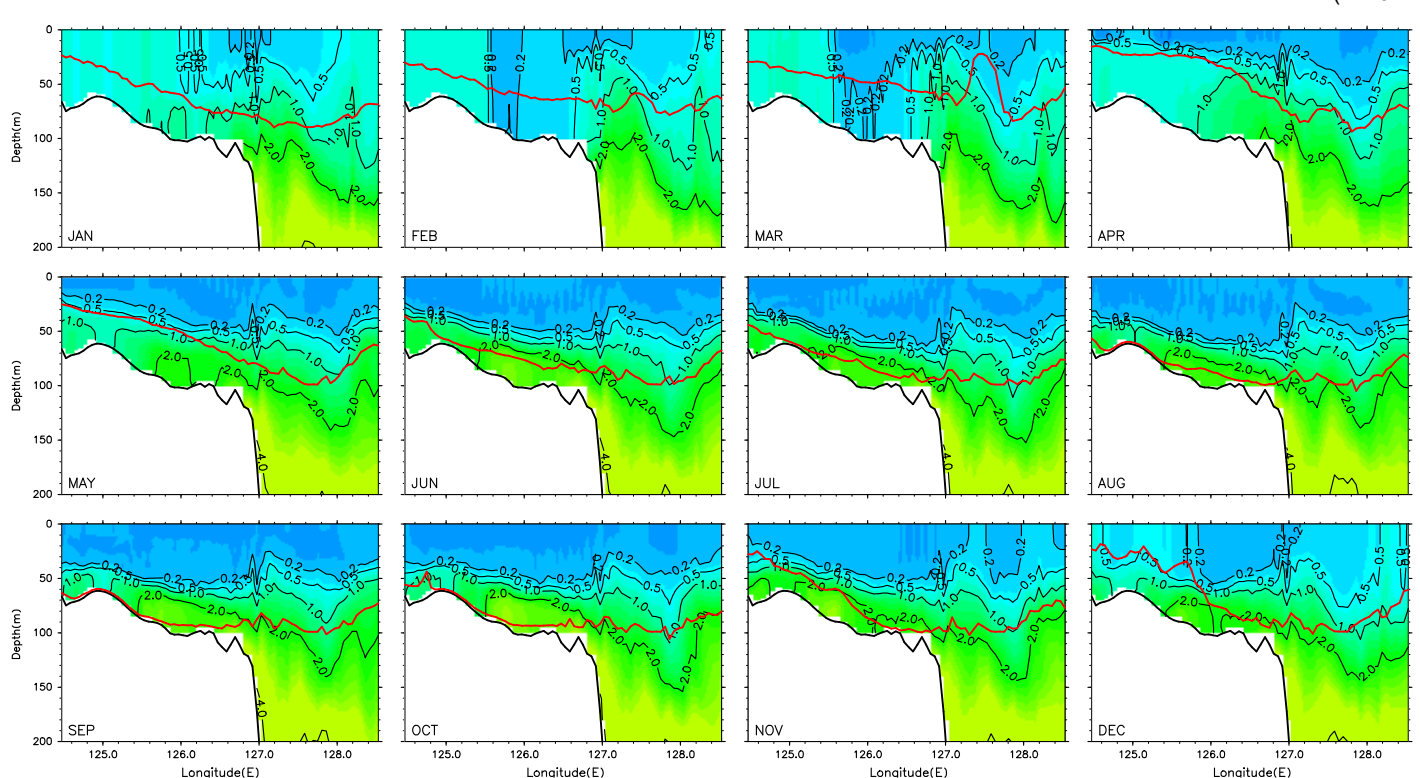

Fig. 15. The anomaly of monthly DIN $\left(\mathrm{mmol} \mathrm{m}^{-3}\right)$ along the PN line between the sensitivity experiment, in which the oceanic nutrients are enriched by $30 \%$, and the control experiment. Red lines denote euphotic depth. 

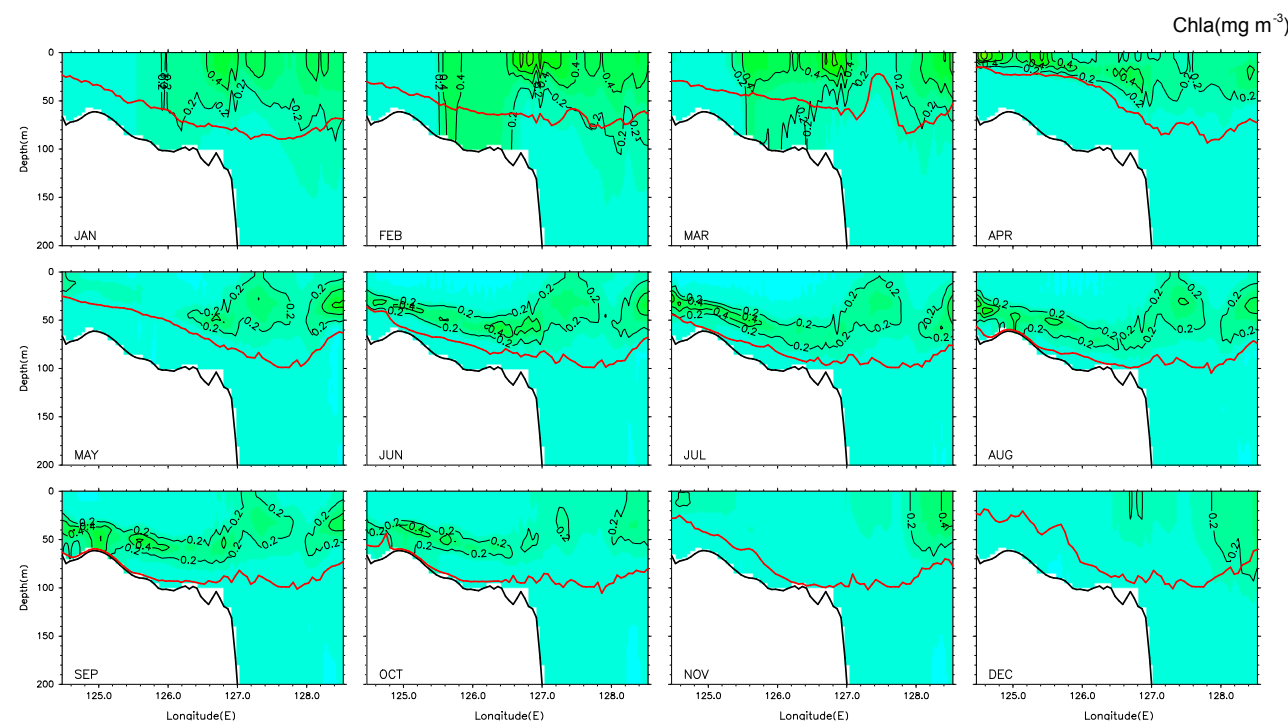

Fig. 16. The same as Fig. 15 but for chlorophyll $a\left(\mathrm{mg} \mathrm{m}^{-3}\right)$.

Table 3. Annual onshore fluxes of nutrients across the $200-\mathrm{m}$ isobath in control and four sensitivity experiments. The positive flux is defined as onshore direction and the unit is $\mathrm{kmol} \mathrm{s}^{-1}$. "ctl" denotes the control experiment while "+10\%"-"+40\%" denote the sensitivity experiments, in which the concentration of oceanic nutrients in the Kuroshio water was artificially increased by 10-40\%, respectively. The values in brackets denote the ratios of flux increases in sensitivity experiments to the initial flux in the control experiment.

\begin{tabular}{llllll}
\hline & ctl & $+10 \%$ & $+20 \%$ & $+30 \%$ & $+40 \%$ \\
\hline DIN & 9.4 & $10.4(+10.8 \%)$ & $11.4(+21.5 \%)$ & $12.3(+32.0 \%)$ & $13.3(+42.3 \%)$ \\
DIP & 0.72 & $0.80(+11.2 \%)$ & $0.88(+22.3 \%)$ & $0.96(+33.2 \%)$ & $1.03(+44.1 \%)$ \\
SIL & 18.2 & $20.4(+11.7 \%)$ & $22.5(+23.3 \%)$ & $24.6(+34.8 \%)$ & $26.6(+46.2 \%)$ \\
\hline
\end{tabular}

the same ratio (Table 3). This is a natural result since the onshore flux of volume does not change in all of these calculations. However, there is also an apparent difference in the increased ratio of the three nutrient elements. The increased ratio of silicate was highest, while that of DIN was lowest. Such differences are probably related to the different elemental ratios of nutrients in the pre-existing water over the shelf that was transported in an offshore direction across the shelf break, and in the oceanic water that was transported in an onshore direction.

The ratio of DIN to DIP in the total onshore flux of nutrients in the control experiment was $13(=9.4 / 0.72$ in Table 3), which is less than the Redfield ratio of 16 used in the model calculation; the average ratio of DIN to silicate is $\sim 0.5$, which is also less than the ratio of $16: 15$ used in the model calculation; the average ratio of silicate to DIP was 25 , which is higher than the ratio of 15 used in the model calculation. As shown in Fig. 12, the additional oceanic nutrients can reach the offshore area of the Changiiang estuary, where the limiting nutrient has been reported to be DIP based on the observed atomic ratio of DIN, DIP and silicate (Liu et al., 2003). In our simulation, the average ratio of DIN to DIP in Changjiang River water was 59, the average ratio of DIN to silicate was 0.35 , and the average ratio of silicate to DIP was 166 . Consequently, nutrient limitation in our simulation was also dependent on DIP for the Changjiang diluted water that spreads offshore of the Changjiang estuary in summer. This is why we obtained a negative anomaly in that region for DIN between the control experiment and sensitivity experiments (Fig. 12). Therefore, the supply of oceanic nutrients to the shelf contributed to phytoplankton growth not only by themselves but also from their element ratio, because the low ratio of DIN to DIP in the Kuroshio water promotes the consumption of DIN in the pre-existing shelf water.

\section{Conclusions}

By combining a low trophic level ecosystem model with a hydrodynamic model, we were able to reproduce the general features of spatial and temporal variations in nutrients and chlorophyll $a$ in the Yellow Sea and ECS. Horizontally, the area with high chlorophyll $a$ concentration first appeared in the central Yellow Sea in spring, and then moved toward coastal zones in summer; in the ECS, the area with high chlorophyll $a$ concentration first appeared northeast of 
Taiwan, i.e., at the outer shelf and shelf break in winter, and then gradually moved toward the middle and inner shelves in summer and autumn. Vertically, high chlorophyll $a$ concentration appeared in the surface layer in spring at the middle and outer shelves and in the subsurface layer in summer and autumn, corresponding to changes in light intensity and nutrients.

The onshore flux of volume and nutrients across the shelf break, calculated from the model results, have noticeable seasonal variations. The onshore volume flux reached a minimum in June and a maximum in November, while the nutrient flux reached a minimum in March and a maximum in November. The difference in their seasonal variation was caused by the difference in nutrient concentrations in the inflow and outflow water across the shelf break. The annual average onshore flux was estimated to be $1.53 \mathrm{~Sv}$ for volume, $9.4 \mathrm{kmol} \mathrm{s}^{-1}$ for DIN, $0.7 \mathrm{kmol} \mathrm{s}^{-1}$ for DIP, and $18.2 \mathrm{kmol} \mathrm{s}^{-1}$ for silicate. Along the shelf break of the ECS, areas northeast of Taiwan and southwest of Kyushu supply onshore volume and nutrient fluxes, whereas the middle shelf break between them provides an offshore volume and nutrient flux.

By artificially increasing the concentration of oceanic nutrients in the Kuroshio water, we confirmed the contribution of oceanic nutrients to primary production over the shelf of the ECS. The additional oceanic nutrients were distributed in the bottom layer from the shelf break to the offshore region of the Changjiang estuary from spring to summer, and appeared in the surface layer mainly from autumn to winter. The contribution of oceanic nutrients to primary production over the shelf can be found not only in the surface layer (mainly at the outer shelf and shelf break in winter and in the region outside the turbidity zone of the Changjiang estuary in summer), but also in the subsurface layer over the shelf from spring to autumn.

Since the ratio of the three nutrient elements in the Kuroshio water was different from that in the pre-existing shelf water, in particular from the Changjiang plume, the contribution of oceanic nutrients to photosynthesis over the shelf promoted the consumption of residual DIN in that area. Therefore, it can be concluded that the supply of oceanic nutrients to the shelf of the ECS contributes to phytoplankton growth not only in itself but also because of its elemental ratio.

Acknowledgements. The authors thank Jing Zhang at East China Normal University for the discussions concerning the model results. Liang Zhao was supported by the National Science Foundation of China (No. 40806001 and 40830854), National Basic Research Program of China (973 Program 2010CB428904) and Global COE Program from the Japanese Ministry of Education, Culture, Sports, Science and Technology. Xinyu Guo was supported by the Global COE Program from the Japanese Ministry of Education, Culture, Sports, Science and Technology, JSPS KAKENHI (21310012), and Overseas, Hong Kong \& Macao Scholars Collaborated Researching
Fund from National Science Foundation of China (No. 41028006). We appreciate the critical comments from the three reviewers.

Edited by: P. Chapman

\section{References}

Aksnes, D. L., Ulvestad, K. B., Balino, B. M., Berntsen, J., Egge, J. K., and Svendsen, E.: Ecological modelling in coastal waters: Towards predictive physical-chemical-biological simulation models, Ophelia. 41, 5-36, 1995.

Blumberg, A. F. and Mellor, G. L.: A description of a three dimensional coastal ocean circulation model, in: Three-Dimensional Coastal Ocean Models, edited by: Heaps, Coastal and Estuarine Series, No. 4, N., Amer. Geophys. Union, 1-16, 1987.

Chen, C. T. A.: Distributions of Nutrients in the East China Sea and the South China Sea Connection, J. Oceanogr., 64(5), 737-751, 2008.

Chen, C. T. A.: Chemical and physical fronts in the Bohai, Yellow and East China seas, J. Marine Syst., 78(3), 394-410, 2009.

Chen, C. T. A. and Wang, S. L.: Carbon, alkalinity and nutrient budgets on the East China Sea continental shelf, J. Geophys. Res., 104(C9), 20675-20686, 1999.

Chen, D. X.: Marine Atlas of Bohai Sea, Yellow Sea, East China Sea, Hydrology, edited by: Chen, G. Z., China Ocean Press, Beijing, 530 pp., 1992.

Chen, Y. L. L., Chen, H. Y., Gong G. C., Lin, Y. H., Jan, S., and Takahashi, M.: Phytoplankton production during a summer coastal upwelling in the East China Sea, Cont. Shelf Res., 24, 1321-1338, 2004.

Dobson, F. W. and Smith, S. D.: Bulk models of solar radiation at sea, Q. J. Roy. Meteorol. Soc., 114, 165-182, 1988.

Garcia, H. E., Locarnini, R. A., Boyer, T. P., and Antonov, J. I.: World Ocean Atlas 2005, Volume 3: Dissolved Oxygen, Apparent Oxygen Utilization, and Oxygen Saturation, edited by: Levitus, S., NOAA Atlas NESDIS 63, US Government Printing Office, Washington, DC, USA, 342 pp., 2006a.

Garcia, H. E., Locarnini, R. A., Boyer, T. P., and Antonov, J. I.: World Ocean Atlas 2005, Volume 4: Nutrients (phosphate, nitrate, silicate), edited by: Levitus S., editor, NOAA Atlas NESDIS 64, U.S. Government Printing Office, Washington, DC, USA, 396 pp., $2006 b$.

Guo, X., Hukuda, H., Miyazawa, Y., and Yamagata, T.: A Triply Nested Ocean Model for Simulating the Kuroshio-Roles of Horizontal Resolution on JEBAR, J. Phys. Oceanogr., 33, 146-169, 2003.

Guo, X., Miyazawa, Y., and Yamagata, T.: The Kuroshio onshore intrusion along the shelf break of the East China Sea: the origin of the Tsushima Warm Current, J. Phys. Oceanogr., 36, 22052231, 2006.

Isobe, A.: Recent advances in ocean circulation research on the Yellow Sea and East China Sea shelves. Journal of Oceanography, 64, 569-584, 2008.

Isobe, A. and Matsuno, T.: Long-distance nutrient-transport process in the Changjiang river plume on the East China Sea shelf in summer, J. Geophys. Res., 113, C04006, doi:10.1029/2007JC004248, 2008.

Jacobs, G. A., Hur, H. B., and Riedlinger, S. K.: Yellow and East China Seas response to winds and currents, J. Geophys. Res., 
105, 21947-21968, 2000.

Kalnay, E., Kanamitsu, M., Kistler, R., and Collins, W.: The NCEP/NCAR 40-year reanalysis project, B. Am. Meteorol. Soc., 77(3), 437-471, 1996.

Liu, S. M., Zhang, J., Chen, H. T., Wu, Y., Xiong, Y., and Zhang, Z. F.: Nutrients in the Changjiang and its tributaries, Biogeochemistry, 62(1), 1-18, 2003.

Liu, S. M., Hong, G.-H., Zhang, J., Ye, X. W., and Jiang, X. L.: Nutrient budgets for large Chinese estuaries, Biogeosciences, 6 , 2245-2263, doi:10.5194/bg-6-2245-2009, 2009.

Mellor, G. L.: Users guide for a three-dimensional, primitive equation, numerical ocean model, Program in Atmospheric and Oceanic Sciences, Princeton University, USA, 53 pp., 2003.

Moll, A.: Regional distribution of primary production in the North Sea simulated by a three-dimensional model, J. Marine Syst. 16(1-2), 151-170, 1998.

Risien, C. M. and Chelton, D. B.: A global climatology of surface wind and wind stress fields from eight years of QuikSCAT scatterometer data, J. Phys. Oceanogr., 38, 2379-2413, 2008.

Sarmiento, J. L. and Gruber, N.: Ocean biogeochemical dynamics, Princeton University Press, USA, 503 pp., 2006.

Skogen, M. D. and Moll, A.: Interannual variability of the North Sea primary production: comparison from two model studies, Cont. Shelf Res., 20(2), 129-151, 2000.

Skogen, M. D. and Søiland, H.: A user's guide to NORWECOM v2.0, a coupled 3 dimensional physical chemical biological ocean-model, in: The NORWegian Ecological Model system, Bergen, Institute of Marine Research, 42, Technical Report Fisken og Havet 18/98, available online at: http://www.imr.no/ $\sim$ morten/norwecom/userguide2_0.ps.gz, 1998.

Skogen, M. D., Svendsen, E., Berntsen, J., Aksnes, D., and Ulvestad, K. B.: Modeling the primary production in the North Sea using a coupled three-dimensional Physical-Chemical-Biological Ocean Model, Estuarine Coast. Shelf Sci., 41, 545-565, 1995.

Valiela, I.: Marine Ecological Processes, Springer, New York, USA, 686 pp., 1995.
Wan, X. F., Wu, Z. F., Chang, Z. Q. and Zhang, X. L.: Reanalysis of atmospheric flux of nutrients to the South Yellow Sea and the East China Sea, Marine Environmental Science, 21(4), 14-18, 2002.

Wang, W. J. and Jiang, W. S.: Study on the Seasonal Variation of the Suspended Sediment Distribution and Transportation in the East China Seas Based on SeaWiFS Data, Journal of Ocean University of China, Ocean. Coast. Sea Res., 7(4), 385-392, 2008.

Wang, Y. H.: Marine Atlas of Boshi Sea, Yellow Sea, East China Sea, Chemistry, edited by: Chen, G. Z., China Ocean Press, Beijing, 257 pp., 1991.

Wang, B. D., Wang, X. L., and Zhang, R.: Nutrient conditions in the Yellow Sea and the East China Sea, Estuarine, Coast. Shelf Sci., 58, 127-136, 2003.

Wang, Q., Guo, X. Y., and Takeoka H.: Seasonal variations of the Yellow River plume in the Bohai Sea: A model study, J. Geophys. Res., 113, C08046, doi:10.1029/2007JC004555, 2008.

Wei, H., Sun, J., Moll, A., and Zhao, L.: Phytoplankton dynamics in the Bohai Sea-observations and modeling, J, Marine Syst, , 44, 233-251, 2004.

Wong, G. T. F., Gong, G., Liu, K., and Pai, S.: "Excess nitrate" in the East China Sea, Estuarine Coast. Shelf Sci., 46, 411-418, 1998.

Zhang, J.: Nutrient elements in large Chinese estuaries, Cont. Shelf Res., 16(8), 1023-1045, 1996.

Zhang, G. S., Zhang, J., and Liu, S. M., Characterization of nutrients in the atmospheric wet and dry deposition observed at the two monitoring sites over Yellow Sea and East China Sea, J. Atmos. Chem., 57, 41-57, 2007a.

Zhang, J., Liu, S. M., Ren, J. L., Wu, Y., and Zhang, G. L.: Nutrient gradients from the eutrophic Changjiang (Yangtze River) Estuary to the oligotrophic Kuroshio waters and re-evaluation of budgets for the East China Sea Shelf, Prog. Oceanogr., 74, 449478, $2007 \mathrm{~b}$. 